\title{
Using Information and Communication Technology in Home Care for Communication between Patients, Family Members, and Healthcare Professionals: A Systematic Review
}

\author{
Birgitta Lindberg, Carina Nilsson, Daniel Zotterman, Siv Söderberg, and Lisa Skär \\ Division of Nursing, Department of Health Science, Luleå University of Technology, 97187 Luleå, Sweden \\ Correspondence should be addressed to Birgitta Lindberg; birgitta.lindberg@ltu.se
}

Received 18 November 2012; Revised 17 January 2013; Accepted 3 February 2013

Academic Editor: Carlos De Las Cuevas

Copyright (C) 2013 Birgitta Lindberg et al. This is an open access article distributed under the Creative Commons Attribution License, which permits unrestricted use, distribution, and reproduction in any medium, provided the original work is properly cited.

\begin{abstract}
Introduction. Information and communication technology (ICT) are becoming a natural part in healthcare both for delivering and giving accessibility to healthcare for people with chronic illness living at home. Aim. The aim was to review existing studies describing the use of ICT in home care for communication between patients, family members, and healthcare professionals. Methods. A review of studies was conducted that identified 1,276 studies. A selection process and quality appraisal were conducted, which finally resulted in 107 studies. Results. The general results offer an overview of characteristics of studies describing the use of ICT applications in home care and are summarized in areas including study approach, quality appraisal, publications data, terminology used for defining the technology, and disease diagnosis. The specific results describe how communication with ICT was performed in home care and the benefits and drawbacks with the use of ICT. Results were predominated by positive responses in the use of ICT. Conclusion. The use of ICT applications in home care is an expanding research area, with a variety of ICT tools used that could increase accessibility to home care. Using ICT can lead to people living with chronic illnesses gaining control of their illness that promotes self-care.
\end{abstract}

\section{Introduction}

Due to an ageing population and a shortage of hospital beds, it has become a challenge to find new ways to support and care for people with chronic illness living at home. Living with chronic illness changes the lives of those affected, who are often in need of support and nursing care in their homes [1-3]. eHealth has the potential to become a means of providing good care at home [4], which is especially challenging with regard to this emerging field [5]. eHealth refers to information and communication technology (ICT) tools and services for health, whether the tools are used behind the scenes by healthcare professionals or directly by patients and their relatives [6]. ICT tools can be used to access a wide variety of technological solutions for communication, including text messaging, gathering and monitoring data, diagnosis and treatment at distances, and retrieving electronic health records $[5,7]$. According to the World Health Organization (WHO) [8], eHealth is used in the healthcare for transmission of digital data, including data stored and retrieved electronically to support healthcare, both at the local site and at a distance.

E-Health includes the interaction between patients and health service providers or peer-to-peer communication between patients and/or health professionals. Interest has primarily focused on the use of ICT tools in the care of older [9] and severely chronically ill people [10]. Although ICT has been increasingly used in healthcare in recent years, efforts across countries have been fragmented and could benefit from improved cross-border coordination. eHealth tools and services have been widely introduced and implemented, and the potential benefits ICT can bring people with chronic illness will increase significantly [6].

\section{Aim}

The aim was to review existing studies describing the use of ICT in home care for communication between patients, family members, and healthcare professionals. 
The particular objectives of the review were the following:

(i) to provide an overview of characteristics of studies describing the use of ICT in home care,

(ii) to describe how ICT was used for communication in home care,

(iii) to describe the benefits and drawbacks of the use of ICT in home care.

\section{Method}

The design for conducting this systematic review was guided by DiCenso et al. [11], with the following steps taken: for formulating a research question, conducting a literature search, applying inclusion and exclusion criteria, abstracting data, and undertaking an analysis.

3.1. Selection Criteria. The inclusion criteria for this literature review were set as follows: (1) ICT interventions; (2) communication between any healthcare professionals, patients, and/or family members; (3) studies published in scientific journals; (4) studies published between 2000 and 2010; and (5) in the English language. Criteria for exclusion were ICT interventions that included technological systems not involving people (no active patient acceptance) such as monitoring by camera, alarm systems, and use of ordinary telephones, noting that telephones can be used complementarily to other techniques. Letters, editorials, and news items were also excluded.

3.2. Search Strategy. In the literature search the following electronic bibliographic databases were used: PubMed, Scopus, and CINAHL. Search limits were set to English language studies published in scientific journals from 2000 to June 2010. The search terms and search strategy were customized for each database to search completely and exactly. The search strategy included thesaurus terms (MeSH terms and subject headings) combined with free-text words. Examples of main search terms used were telemedicine, information and communication, ICT, technology, e-health, home care, home, and nursing. To maximize the search results, multiple sets of search terms were used. The search was done until an overlap in the studies was observed. All studies retrieved from the search in databases were imported into a reference manager (EndNote). The literature searches resulted in 1,276 studies; after duplicates were discarded by EndNote, 923 studies remained. A search alert was created to get the latest published studies, which resulted in 11 additional studies. The final total to be reviewed was 934. The literature search was performed with support from librarians.

3.3. Selection Process. A first selection was based on titles and abstracts of the 934 studies to identify whether or not they were within the scope of the research question. Next, a selection based on inclusion criteria was conducted, with focus on studies of ICT applications used in home care. After this selection, a total of 320 studies remained for closer review. The full-text version of the studies was then read and initially categorized based on type of communication applied in the studies. Two authors read all the studies independently. To increase reliability they discussed ambiguities of inclusion criteria until consensus was reached. This reduced the number to 139 studies relevant to the research question. However, nine relevant studies were unavailable both electronically and in paper form, which thereby were excluded from this study, leaving 130 studies. The selection process for the studies reviewed is presented in Figure 1.

3.4. Quality Appraisal. All eligible studies $(n=130)$ were evaluated for scientific quality on a three-grade scale: high scientific quality, good scientific quality, and fair scientific quality. The grading system is used by The Swedish Council on Technology Assessment in Health Care (SBU) for systematic reviews [12-14]. The quality appraisal was performed in accordance with a previously presented method for quality appraisal [15-18], which was chosen to be appropriate. In appraising the scientific quality of each study, protocols were used to extract data. Different protocols were used for studies with a quantitative approach and for studies with a qualitative approach. In the protocol for quantitative studies the items focused mainly on exclusion, sample procedures, intervention, dropouts, randomization, similarity of groups, blinding, outcomes, statistical procedures, ethical considerations, validity and reliability of instruments used, and possibility of generalization of results. In the protocol for qualitative studies the items focused mainly on context, ethical reasoning, procedure of sample, data collection, analysis procedures, saturation, clarity and logic of results, theoretical framework, theory generation, and description of main results. The protocols contained questions to be answered with yes/no/unclear and additional space to comment on the relevance of each item and for the extracted data. The number of questions answered yes was divided by the total number of questions and thereafter converted to percentage. Willman et al. [15] state that the use of percentage makes it possible to weight and compare different study's methodologies. As recommended [15] the percentage was transformed to high scientific quality (80-100\%), good scientific quality (70-79\%), and fair scientific quality (60$69 \%)$. The studies that scored less than fair were excluded ( $n=23$ ), as they were considered not to be of sufficient scientific quality to be included. The quality appraisal was performed by two of the authors, initially together to obtain an equal assessment, but thereafter independently. When uncertainties arose, the authors discussed the result of the quality appraisal until consensus emerged. After the quality appraisal was undertaken, 107 studies remained.

3.5. Data Abstraction. The remaining 107 studies were classified as relevant to the research question and met the inclusion and quality criteria for being included in the data abstraction. A list of all included studies can be found in Table 6. Each of the included studies was given an indexation and then categorized according to a number of different areas based on the following characteristics: country of origin, year of publication, study approach, journal, communication 


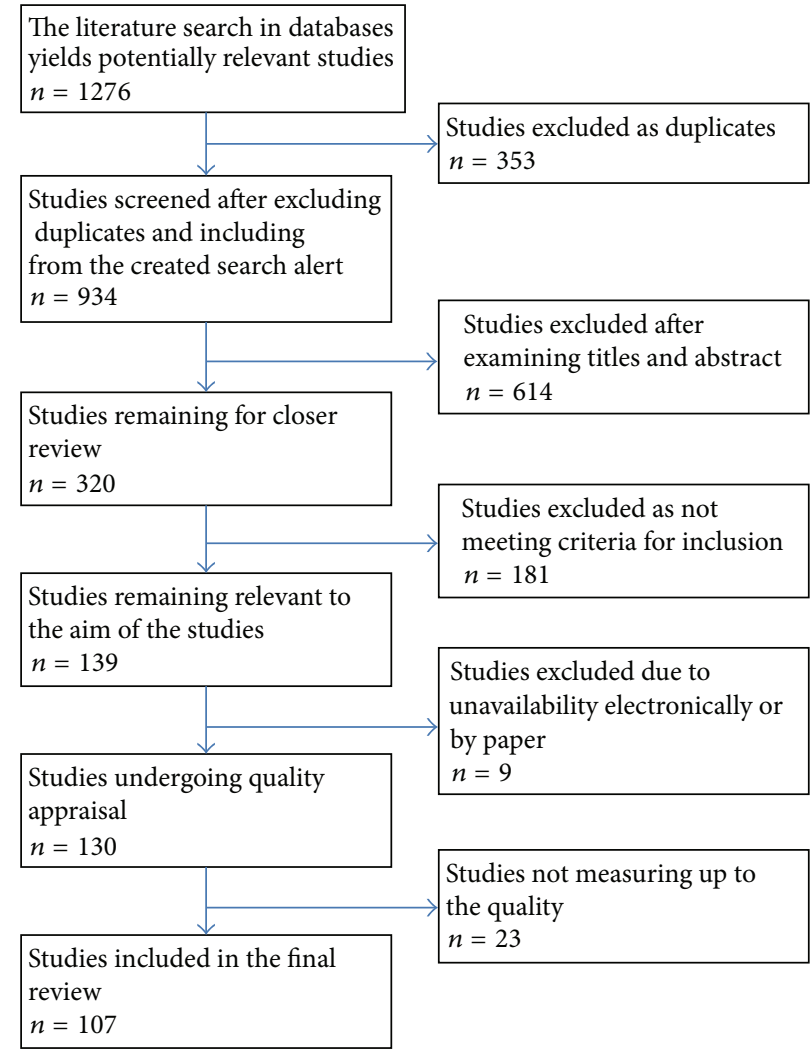

FIGURE 1: Flow chart of search result.

strategies, type of technology, type of communication, disease diagnosis, and quality appraisal. Thereafter, data from each of the included studies were extracted and entered into a matrix.

\section{Results}

The result presentation is divided in two parts; general and specific results.

4.1. General Results. The general results give an overview of characteristics of studies describing the use of ICT applications in home care. The results are summarized in areas including study approach, quality appraisal, publications data, terminology used for defining the technology, and disease diagnosis.

4.1.1. Studies' Approach. Most of the included studies had a quantitative approach. Only about one-fifth had a qualitative approach. Further, some of the studies used mixed methods, with both qualitative and quantitative approaches (Table 1). Twenty-one studies were part of larger projects.

4.1.2. Quality Appraisal. In the critical quality appraisal of all 107 studies, just under half were rated as high scientific quality ( $n=48)$. That number was compared to studies rated as good scientific quality $(n=23)$ and fair to good scientific quality $(n=36)$ (Table 1$)$. When comparing the quality appraisal between qualitative and quantitative approaches, differences could be noted. A greater proportion of the qualitative studies were rated as high scientific quality. In comparison, less than half of the quantitative studies were rated as high scientific quality. The opposite was the case with qualitative and quantitative studies rated as fair scientific quality. Good scientific quality ratings were found in both qualitative and quantitative studies.

4.1.3. Publication Data. All of the 107 included studies were published between January 2000 and June 2010, so only part of year 2010 was included. During this period the number of publications increased by time, with about half of the included studies $(n=53)$ published between 2007 and 2009. Note that 2009 alone represents 23 studies of the total publications (Figure 2).

The studies included were published in 69 different scientific journals. The two most common journals were Journal of Telemedicine and Telecare $(n=15)$ and Telemedicine Journal and e-Health $(n=12)$, together representing almost onequarter of the total number of studies. The rest of the studies $(n=80)$ were spread over a variety of other journals $(n=67)$. The impact factor in the journals ranged between 0.348 and 14,293 .

The majority of the studies were performed in North America $(n=67)$. About one-third of the studies were done in Europe $(n=34)$, with United Kingdom, Sweden, and Italy being the most prominent. Only a few studies $(n=6)$ were conducted outside North America and Europe; those were done in Asia $(n=5)$ and Australia $(n=1)$. Three studies were 


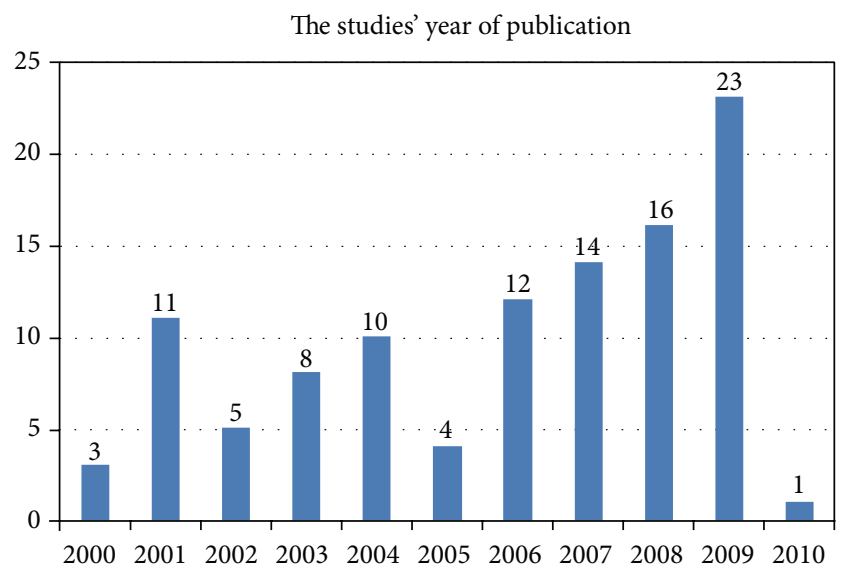

FIgURE 2: Number of studies published per year between 2000 and June 2010.

TABLE 1: Sample data representation.

\begin{tabular}{lccc}
\hline \multirow{2}{*}{ Study quality } & \multicolumn{3}{c}{ Study method (number of studies) } \\
& Qualitative & Quantitative & Mixed (12) \\
\hline High scientific quality & $15(71 \%)$ & $29(39 \%)$ & $4(33 \%)$ \\
Good scientific quality & $4(19 \%)$ & $17(23 \%)$ & $2(17 \%)$ \\
Fair scientific quality & $2(10 \%)$ & $28(38 \%)$ & $6(50 \%)$ \\
\hline
\end{tabular}

carried out in cooperation between different countries, but only one study was a combined study involving the continents of North America and Europe (Table 2).

4.1.4. Terminology Used for Defining the Technology. The results show that 13 different terms were used to define the technology utilized to increase accessibility to home care services and home nursing. The most frequently used terms were telehealth, telemedicine, technology, and telecare. Telehealth and telemedicine together $(n=59)$ account for more than half of the terms used in the included studies. Other terms used three times or more were e-Health, ICT/IT, telehealthcare, telemonitoring, and telenursing. Further, in some studies other terms were used as follows: e-rehabilitation, teleassistance, and telerehabilitation (Table 3).

4.1.5. Disease Diagnosis. The ICT applications were used in healthcare for a wide range of different conditions through the life span. In the majority of the studies $(n=86)$, the technology was developed specifically for supporting people with chronicle illness living at home. The most frequent diseases studied were heart and lung diseases, chronic wounds, diabetes, cancer, and stroke. Chronic illness was used in 12 studies without any definition of the specific disease. Other conditions were, for example, infectious diseases, spinal cord injuries, and end-of-life care. A number of studies included did not specify the diagnoses (Figure 3 ).

4.2. Specific Results. The specific results describe how ICT was used for communication in home care and benefits
TABLE 2: Number of studies per country.

\begin{tabular}{lc}
\hline Country & Number of studies \\
\hline USA & 62 \\
UK & 12 \\
Sweden & 7 \\
Italy & 5 \\
Canada & 4 \\
China & 2 \\
Japan & 2 \\
Australia & 1 \\
Austria & 1 \\
Belgium & 1 \\
Denmark & 1 \\
Finland & 1 \\
Germany & 1 \\
Netherlands & 1 \\
Norway & 1 \\
Poland & 1 \\
South Korea & 1 \\
Denmark/Norway & 1 \\
UK/Germany/Netherlands & 1 \\
USA/Netherlands & 107 \\
\hline Total of studies &
\end{tabular}

TABle 3: Number of studies per terminology.

\begin{tabular}{lc}
\hline Terminology & Number of studies \\
\hline Telehealth & 32 \\
Telemedicine & 27 \\
Technology & 11 \\
Telecare & 10 \\
ICT/IT & 7 \\
Telemonitoring & 6 \\
Telenursing & 4 \\
e-Health & 3 \\
Telehealthcare & 3 \\
Telerehabilitation & 2 \\
e-rehabilitation & 1 \\
Teleassistance & 1 \\
\hline Total of studies & 107 \\
\hline
\end{tabular}

and drawbacks within the use of ICT in home care. The results are summarized in the following main areas: type of technology, communications between participants, and benefits and drawbacks of the use of ICT.

4.2.1. Types of Technology. Three fields of applications were found to be prominent in the use of ICT in homecare: video technology, text messages and health monitoring. An important result was that a mix of more than one ICT applications was used in several studies $(n=31)$. A small number of studies included all types of ICT applications above. In some of the studies, a mix of text and pictures and/or audio was used. In a few studies digital images were used. Some 


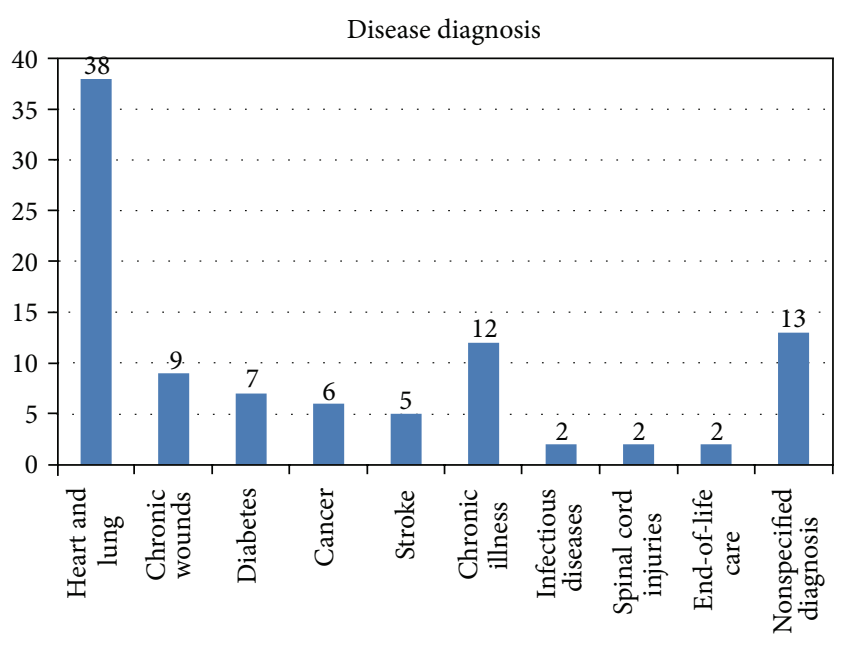

Figure 3: Number of studies per disease diagnosis.

studies did not specify the used ICT application (Table 4).

Video Technology. The most frequently used type of technology was video technology $(n=53)$; the number includes studies using more than one ICT application. In several of those studies ( $n=31)$, the main focus of the intervention was the use of videophones or videoconferencing. Another use of video technology was to complement patient health monitoring $(n=22)$. It is notable that web-based video conferencing was used only in a small number of studies $(n=3)$. In all studies involving parents of children with chronicle illness, video technology was used to communicate.

Video technology was used with different types of applications. Examples of use were guiding patients in their use of medical equipment and to improve self-management, via video-based home telecare services. Another use was teleadvice given by clinical nurse specialists in different areas to community nurses. Videoconferencing was used between patients/family members and healthcare personnel for education and psychosocial or emotional support. Another way to use videoconferencing was to enable interactions between patients and nurses. Consultation via videoconferencing in the patient's home was used instead of visits to the hospital, which enabled access to experts to a greater extent. Virtual nurse visits after, for example, discharge from the hospital, were offered to both patients and family members.

Text Messages. As shown in many studies $(n=30)$, a common way of communicating was via text messages. For sending text messages, websites or web-based programs were used in some studies $(n=10)$. Handheld platforms, such as mobile phones, laptop computers, or text telephones, were used by patients to both send and receive information as well as to communicate $(n=12)$. In other studies $(n=8)$, mobile phones or hand held equipment was used to send text messages.

For example, text messages were used for sending messages to patients with self-care advice as a response to symptoms and test results they had reported. Another way to use
TABLE 4: Overview of ICT applications used in homecare.

\begin{tabular}{|c|c|c|c|}
\hline \multirow{2}{*}{$\begin{array}{l}\text { Number of studies } \\
\text { (main focus for the } \\
\text { study) }\end{array}$} & \multicolumn{3}{|c|}{ Fields of application ${ }^{*}$} \\
\hline & $\begin{array}{l}\text { Video } \\
\text { technology } \\
(n=53)^{* *}\end{array}$ & $\begin{array}{c}\text { Text } \\
\text { messages } \\
(n=30)^{* *}\end{array}$ & $\begin{array}{l}\text { Health } \\
\text { monitoring } \\
(n=52)^{* *}\end{array}$ \\
\hline Type of technology & 49 & 26 & 17 \\
\hline All types & & 4 & \\
\hline $\begin{array}{l}\text { Mix of text and } \\
\text { picture and/or } \\
\text { audio*** }\end{array}$ & & & 6 \\
\hline Digital images & & & 3 \\
\hline $\begin{array}{l}\text { Not specified type of } \\
\text { technology }\end{array}$ & & 2 & \\
\hline Total of studies & & 107 & \\
\hline
\end{tabular}

text messages was by electronic diary for home monitoring to improve communication between patients and healthcare professionals. An electronic messaging programme via computers and mobile phones or e-mail and video mail messages was used, enabling nurses and patients to exchange messages to and from anywhere. Via a symptom management system, patients can receive messages in their daily management of symptoms.

Health Monitoring. About half of the total studies $(n=52)$ included health monitoring, focusing on patients who sent health data to be analyzed by healthcare professionals. In most of the studies that looked at monitoring patient health, text messaging or video technology was used to communicate the data $(n=35)$. Other forms of communication were also used, including the telephone $(n=17)$. Health Buddy, was the most commonly used device for monitoring patient health $(n=8)$. Health Buddy, a system that connects patients in their homes with care providers, is a telehealth device that collects and transmits disease management information about a patient's condition including vital signs, symptoms, and behaviors. Types of patient health data collected from health monitoring systems in real time were, for example, weight, blood pressure, heart rate, and pulse.

4.2.2. Communication between Participants. Different types of communication via ICT were described as being used between participants, who were typically nurses, healthcare professionals, patients, or family members. The most frequent line of communication in the studies was between patients and nurses or other healthcare professionals. ICT was used most for communication between nurses and patients. In 24 studies, the patient was not the focus for communication. Instead, it was common for the technology to be used for communication with family members. In five of the studies with a focus on family members, the ICT was developed for healthcare personnel giving support to parents. In some studies, the communication was merely between healthcare 
TABle 5: Communication between participants.

\begin{tabular}{lc}
\hline Communication & Number of studies \\
\hline Patient-nurse & 49 \\
Patient-other healthcare professionals & 34 \\
Family members-healthcare professionals & 14 \\
Between healthcare professionals & 10 \\
\hline Total of studies & 107 \\
\hline
\end{tabular}

professionals and neither patients nor family members were part of the communication. The review shows that people living with illnesses at home and healthcare professionals gave positive responses from using different ICT applications for healthcare in communication with each other (Table 5).

4.3. Benefits and Drawbacks with the Use of ICT in Home Care. Results of the included studies were predominated by positive responses from the use of different ICT applications in home care from both people living with chronic illnesses and healthcare professionals. For example, healthcare professionals' opinions were that their work was facilitated. Most studies show that communication between healthcare professionals and patients living at home was improved by using various ICT applications, as improvement in management of symptoms in daily life. It was revealed that various ICT applications can be advantageous to use in follow-up care of patients at home. Another benefit of using ICT applications in home care was found to be an improved accessibility. Results from studies show that using ICT in communication in home care can be cost saving but also the opposite. However, the use of ICT cannot replace a face-to-face encounter but can be used as a complement.

\section{Discussion}

The aim of this study was to review existing studies describing the use of ICT in home care for communication between patients, family members, and healthcare professionals. This review provides an overview of characteristics of studies describing the use of ICT applications in home care. The results show that ICT in home care is an expanding field of interest, with a variety of ICT tools beginning to be evaluated significantly. Half of the included studies reviewed represent the year between 2007 and 2009. This may reflect the increased use of the Internet and ICT tools for care management with involvement of patients and family members' participation in care processes. Previous research [19] stated that focus has emerged from being technology focused to taking the users', that is, the patient, family members, and healthcare professionals, perspective into account.

The review shows a trend that most studies were accomplished in North America and Europe, where the United Kingdom, Sweden, and Italy were most prominent. This is noticeable since Italy is one of the European countries in which less than 30 percent of the population uses the Internet on a daily basis. The maturity of the Internet use in daily life is an indicator of how far the digitalization of the healthcare sector should have come [19]. For instance, despite Sweden being a small country, seven of the studies included in this review were performed there, which might be explained by the fact that 75 percent of the population uses the Internet on a daily basis.

This review shows that a wide variety of terms were used in the reviewed studies to define ICT. Most frequently used definitions were telehealth and telemedicine. This is in line with Koch's [7] review of the current state and future trends in home telehealth. The term telehealth has been broadly defined as the use of telecommunication and information technologies for provision of healthcare to individuals at a geographical distance [20]. Telehealth involves a wide variety of specific modalities including telephone-based interactions, Internet-based information, still and live imaging, personal digital assistants, and interactive audio-video communication or television [21]. Furthermore, eHealth is described as the overall umbrella field that includes both ICT and telehealth, combining use of electronic communication and information technology in healthcare [22]. This may explain the results of this review with many different terms used to define the technology.

This review describes how ICT was used for communication in home care, and an interesting result found was that the most frequent type of communication was between patients and healthcare professionals. This indicates that user focus needs to be shifting from tools for professionals to tools for patients and family members. This is in accordance with Koch [7], describing trends toward tools and services not only for professionals, but also for patients and citizens. However from a nursing perspective, there is a lack of knowledge about how to use ICT solutions to meet the needs of people with chronic illness. In specific, by performing qualitative studies people's needs related to living with chronic illness can be elucidated. A challenge in home care will therefore be to use existing ICT tools to meet caring needs of people with chronic illness based on their experiences [23]. From a caring perspective, it is important to understand ICTs impact on quality of life, quality of care, and medical impact of measureable parameters [24].

This review describes benefits and drawbacks when ICT was used for communication in home care. A variety of ICT applications are described in the review. Bardram et al. [23] stated that ICT applications used in home care must take into consideration the role technology should play in the use of patient and healthcare professionals. Neglecting this aspect may lead to technology that not provide the needed support for communication. According to Koch et al. [25], research and practice of health-enabling and ambientassistive technologies may significantly contribute to that technical solutions are explored in a social context and in relation to individual needs. Telehealth systems in the form of online and mobile tools are already opening up the possibilities for reduced hospitalization and an increased home care [26]. Various ICT applications will thereby offer healthcare professionals to become more flexible and able to address the differing needs of individual patients [27], that is, a more person-centred care.

The results of this review show that people living with chronic illnesses and healthcare professionals were positive to 


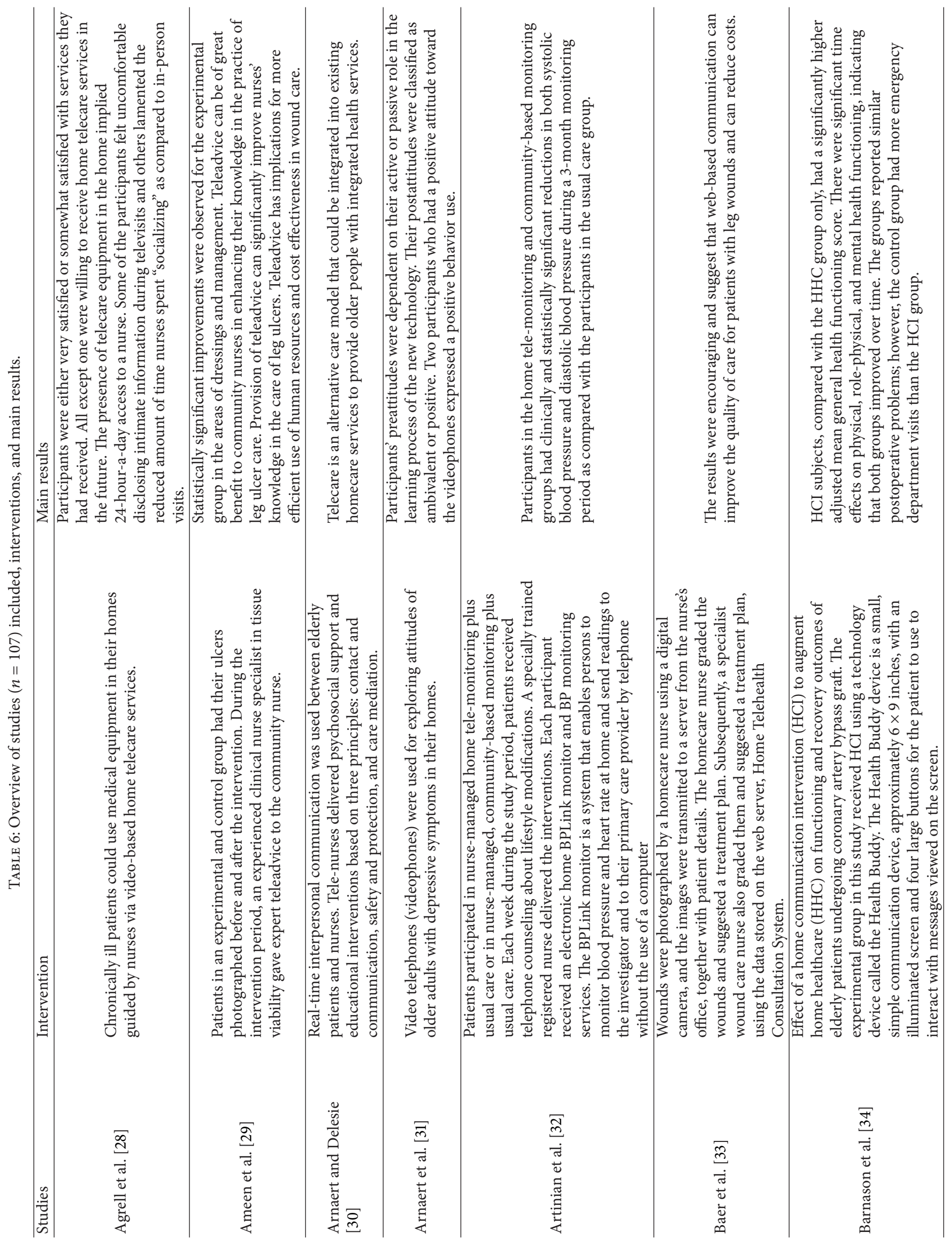




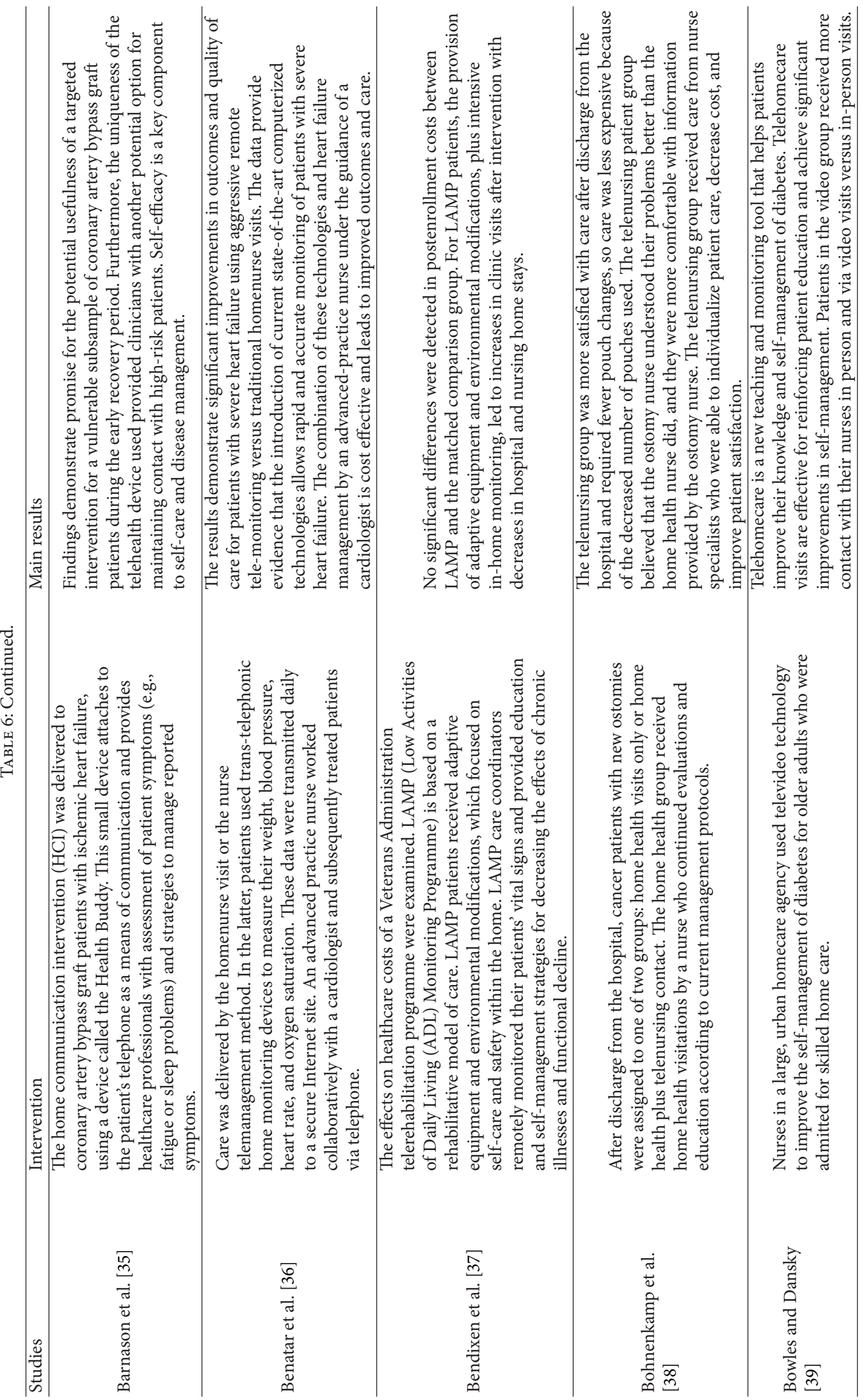




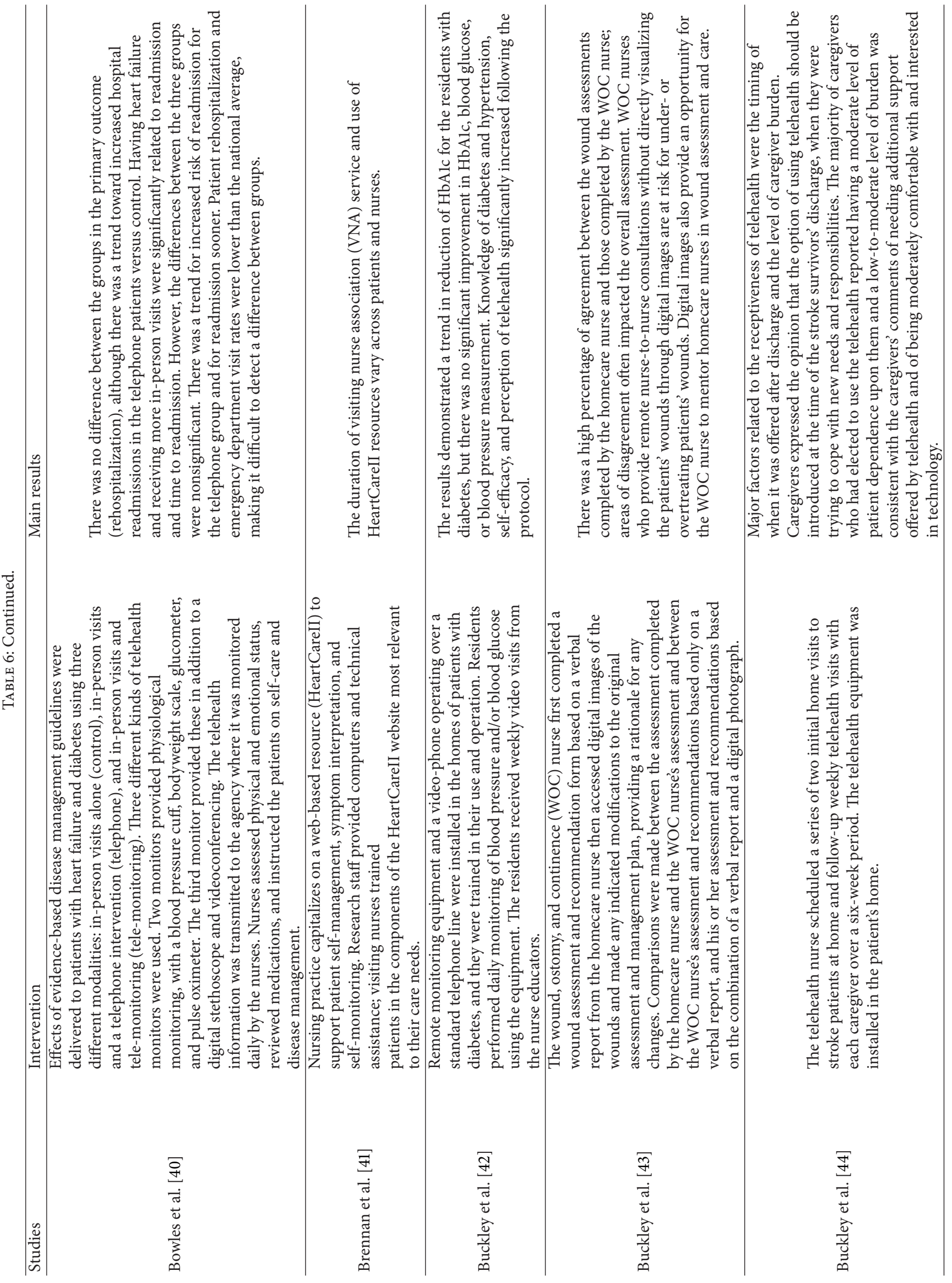




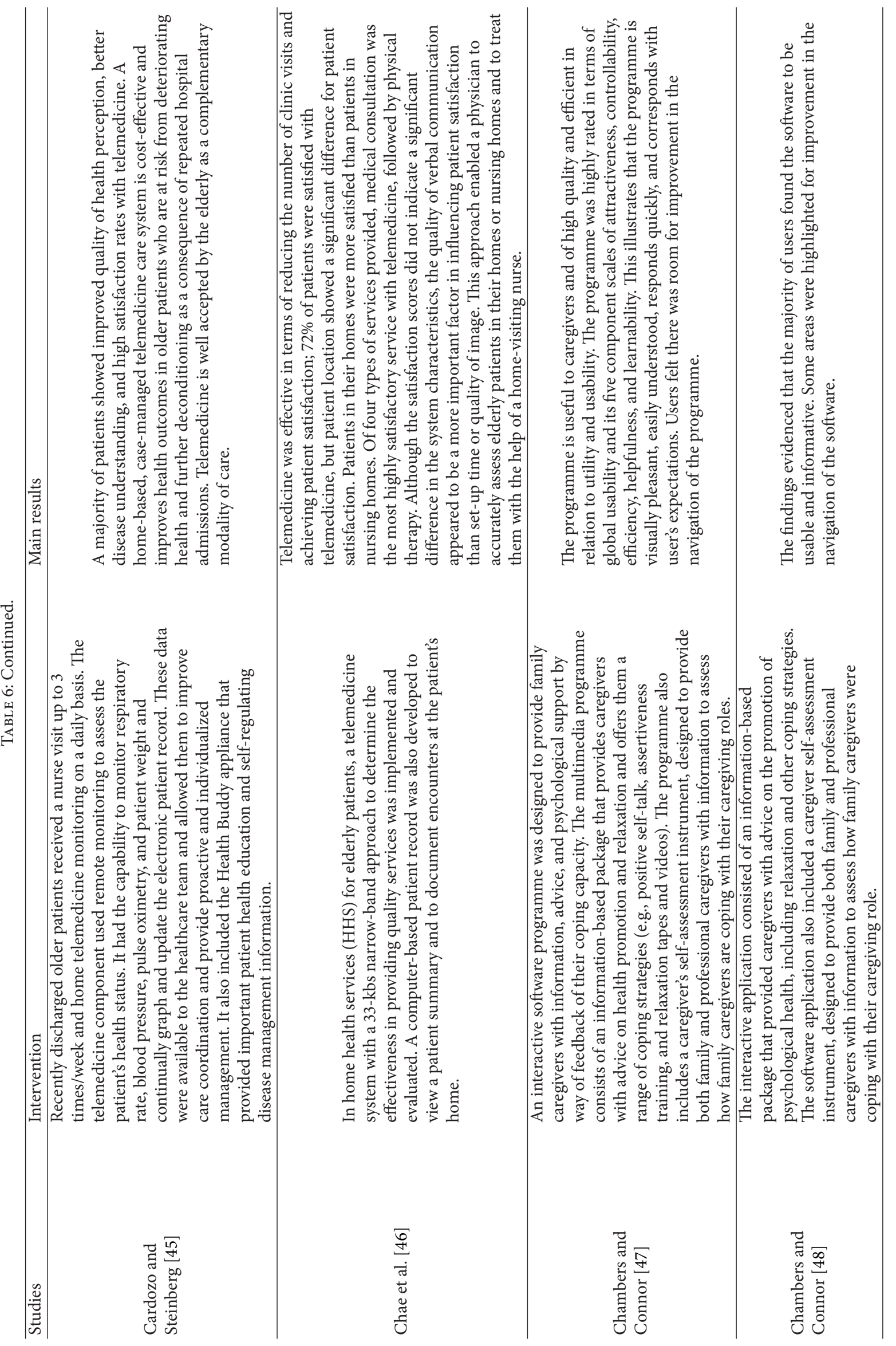




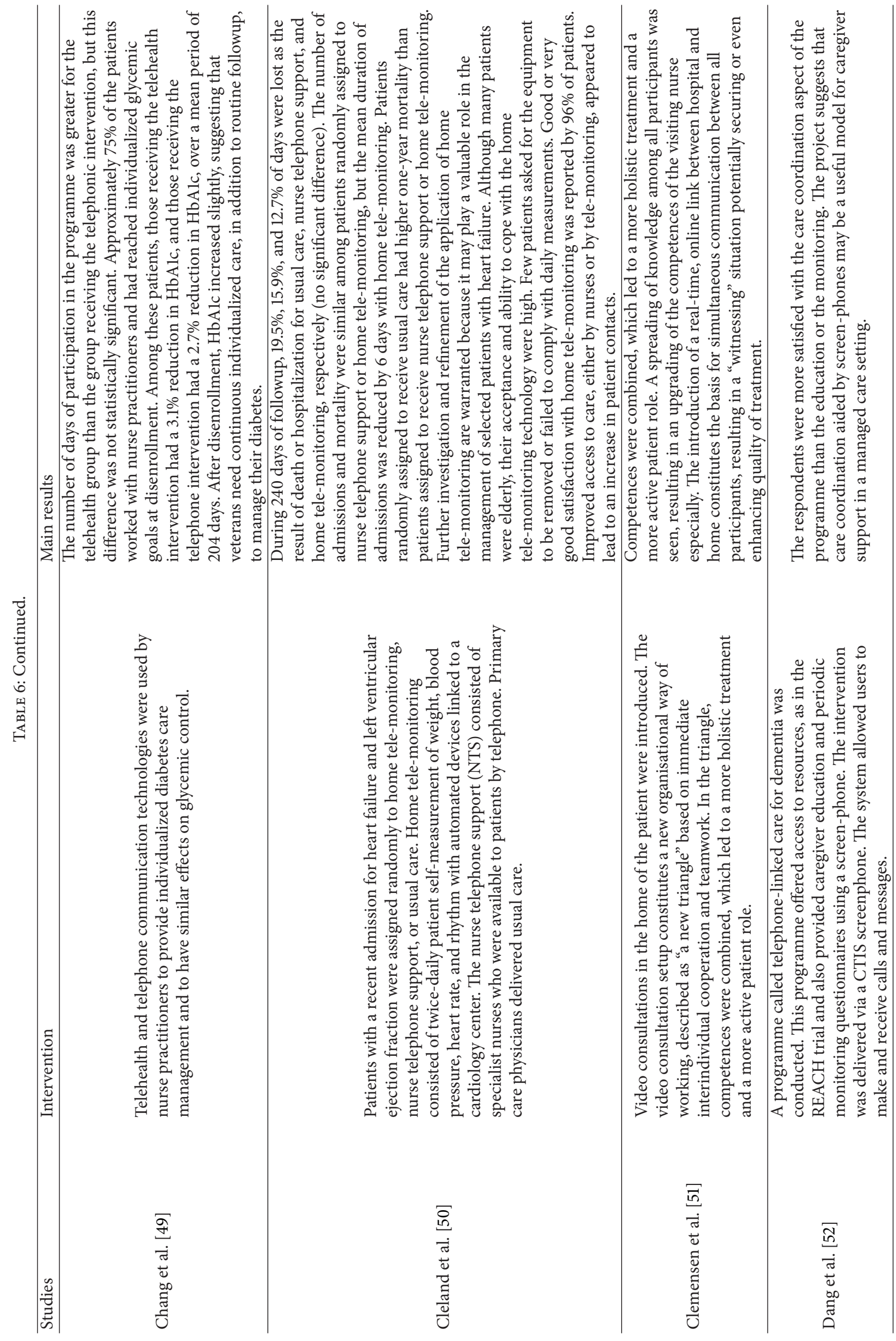




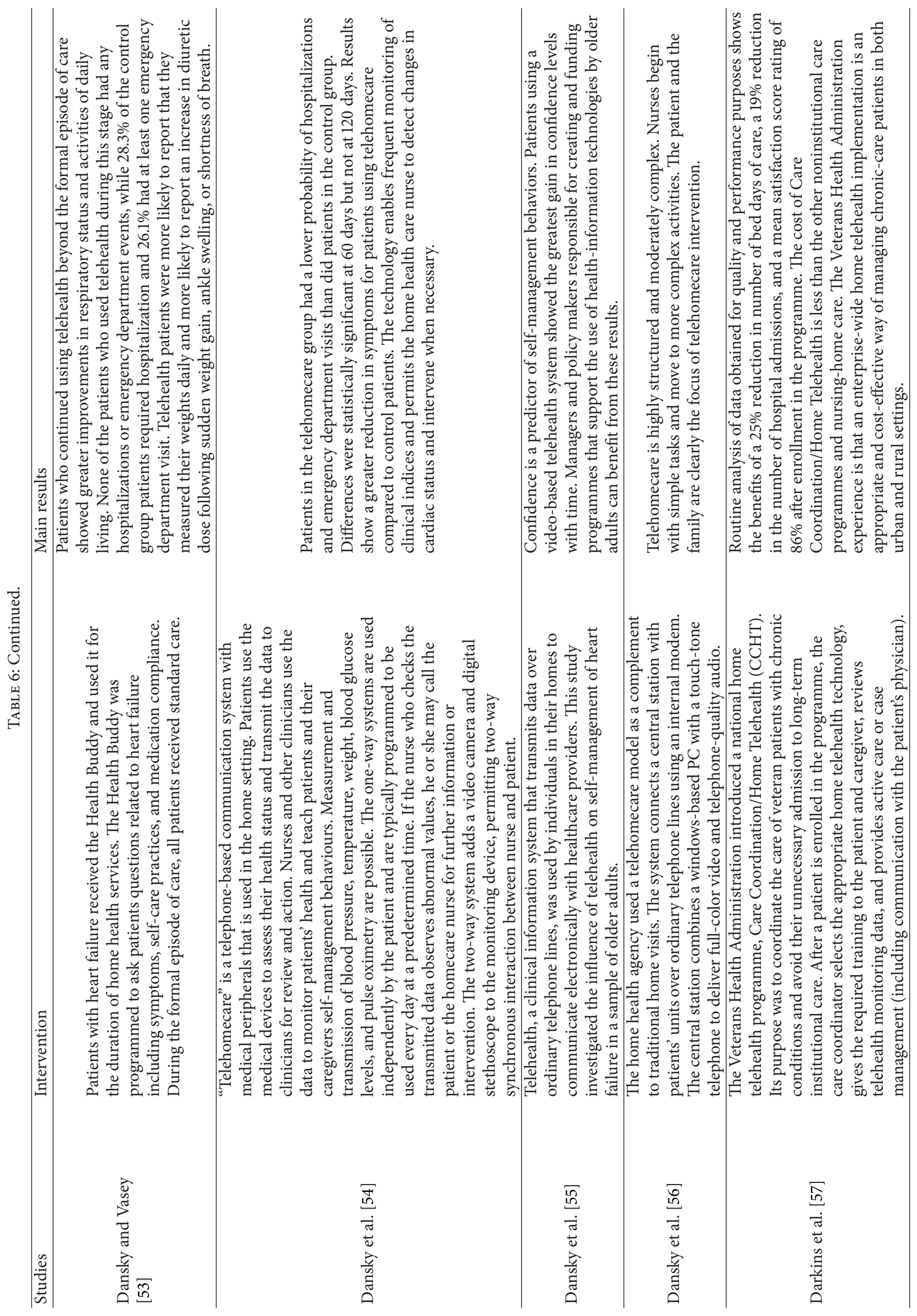




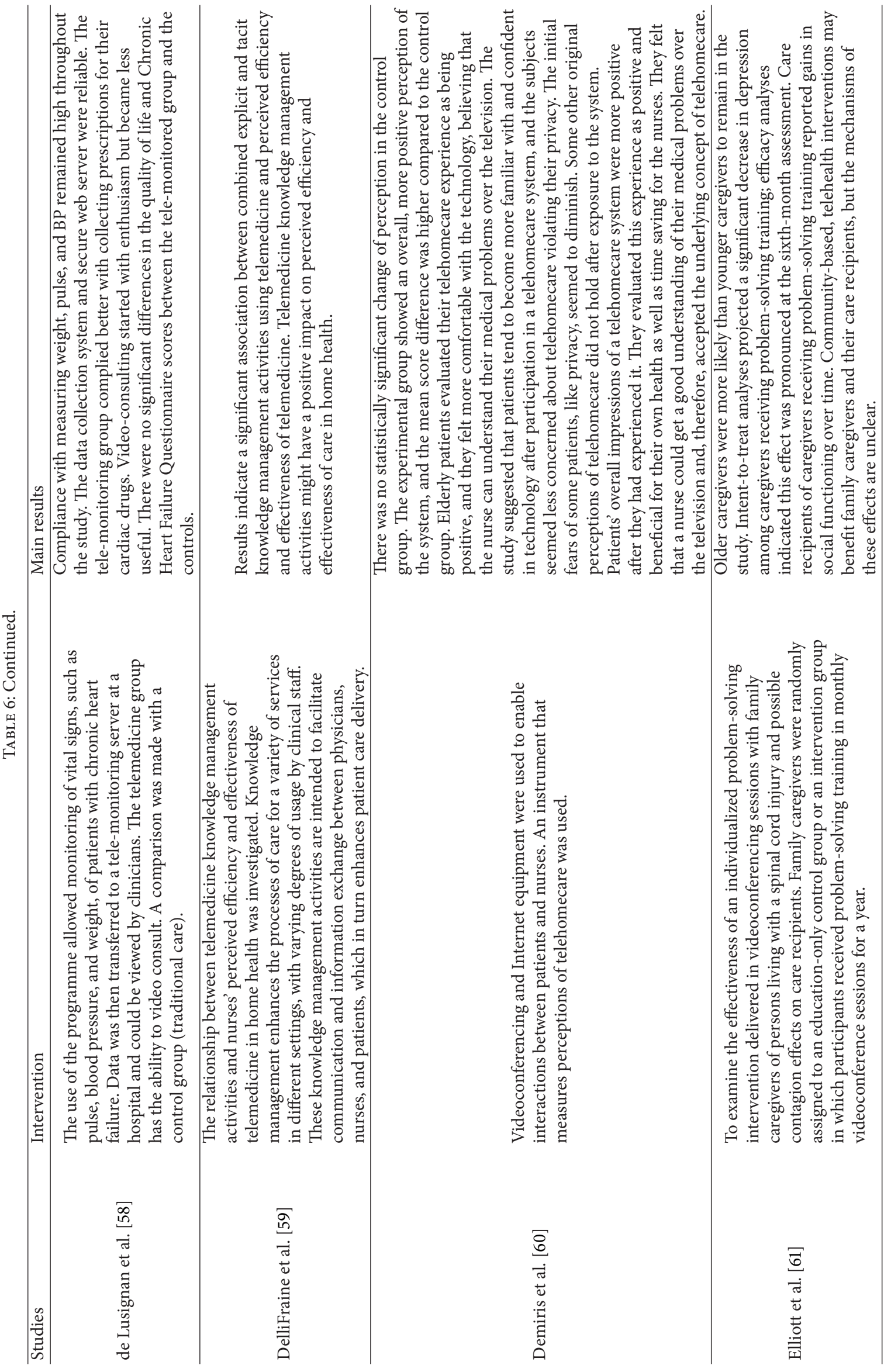




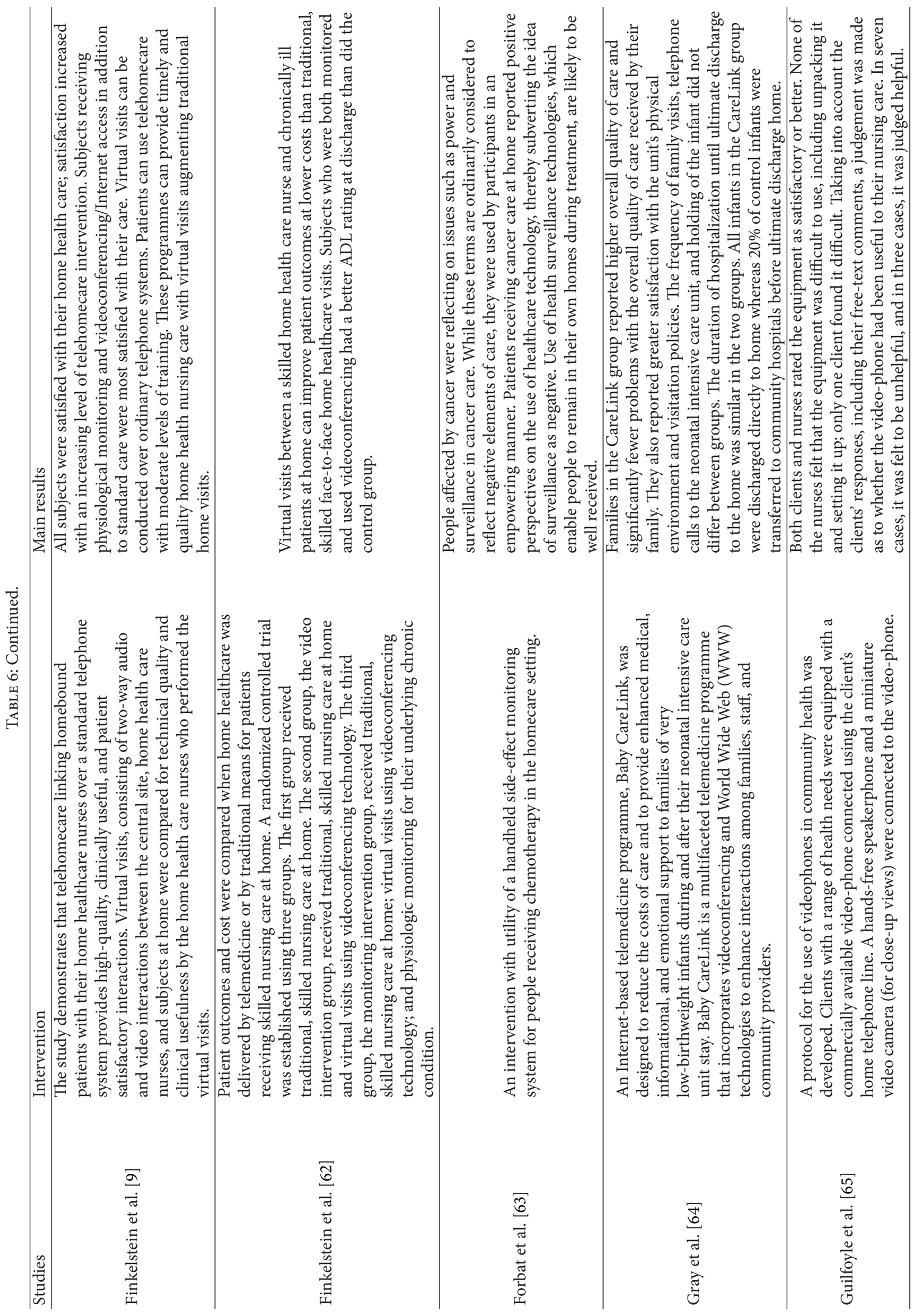




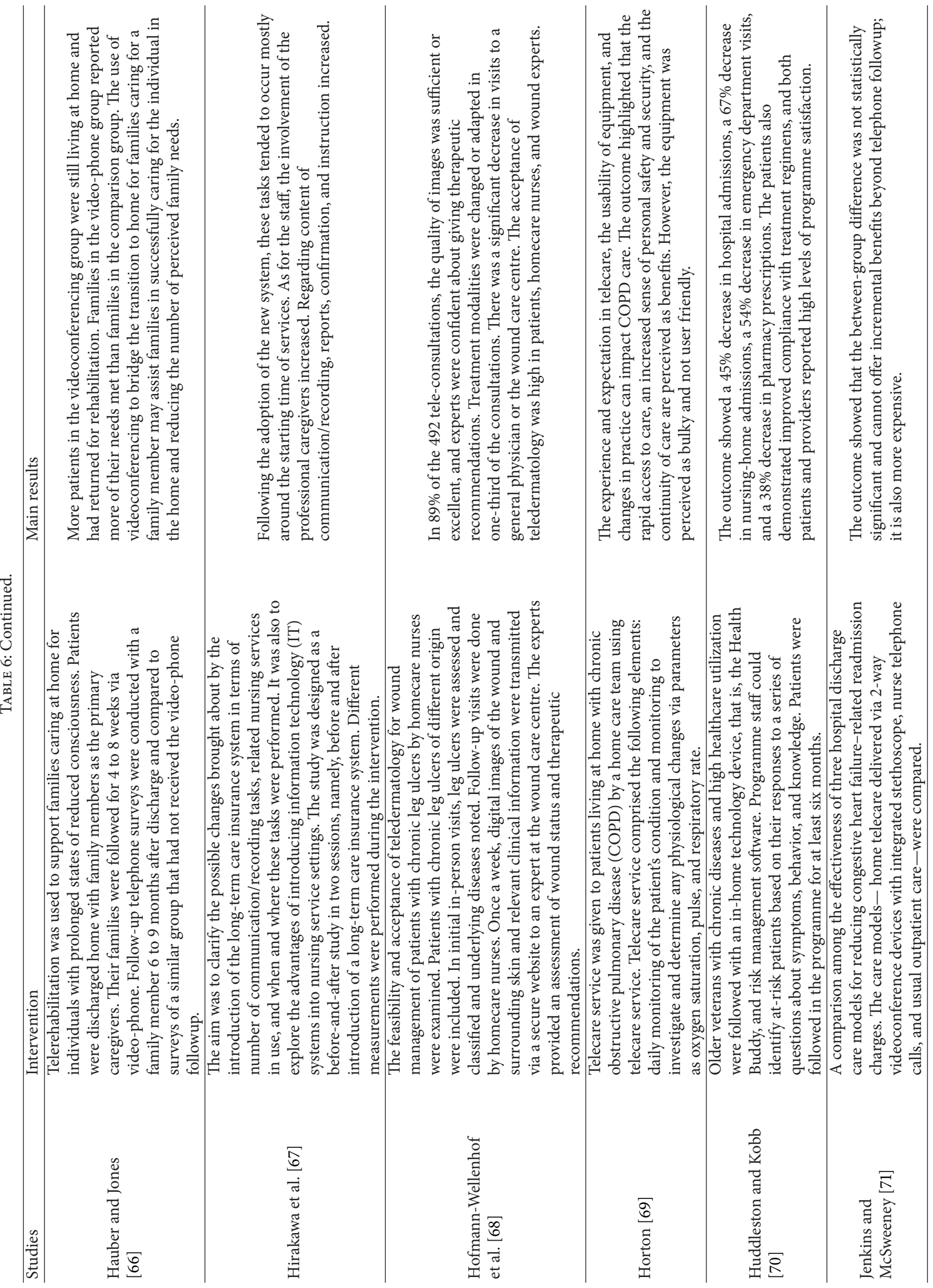




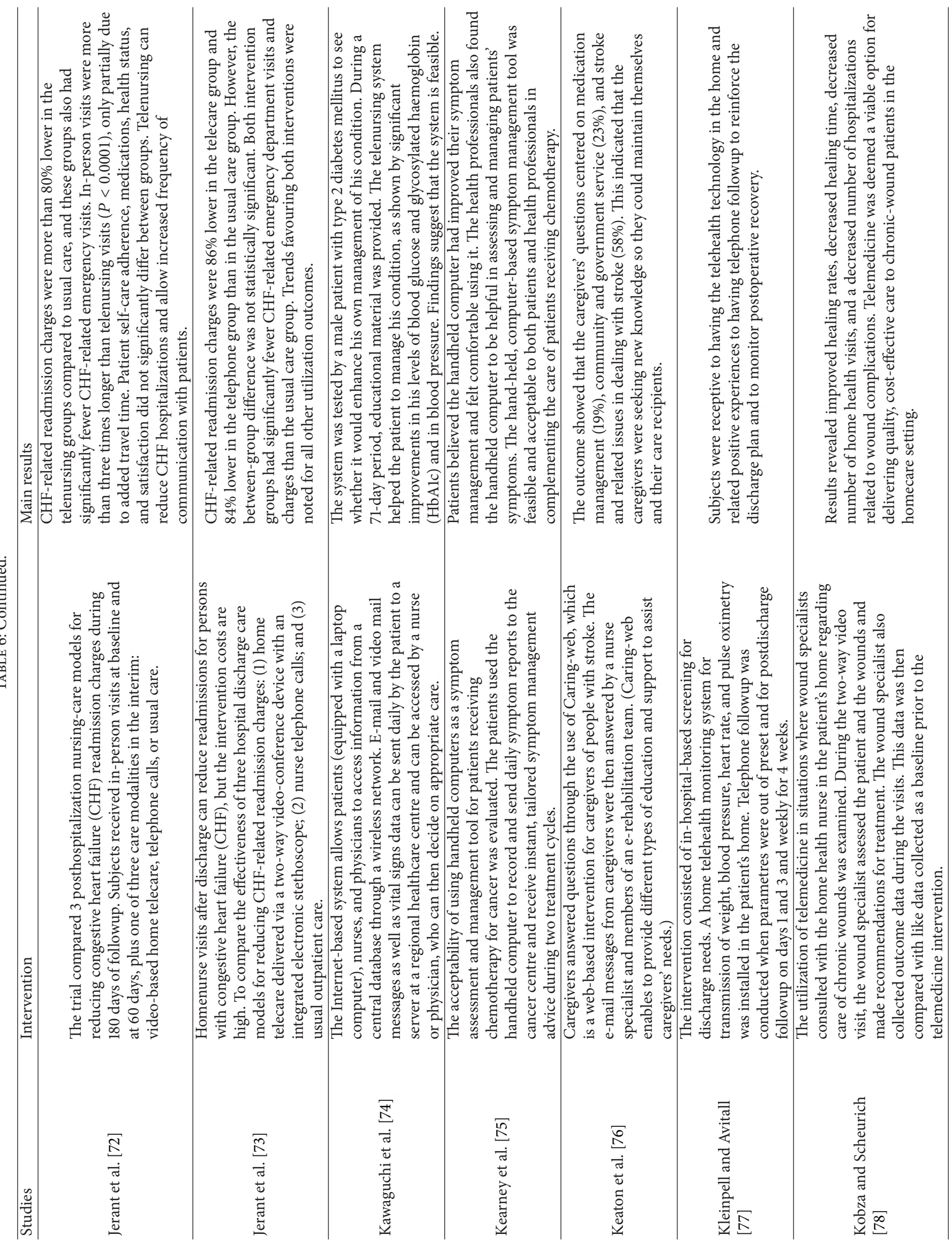




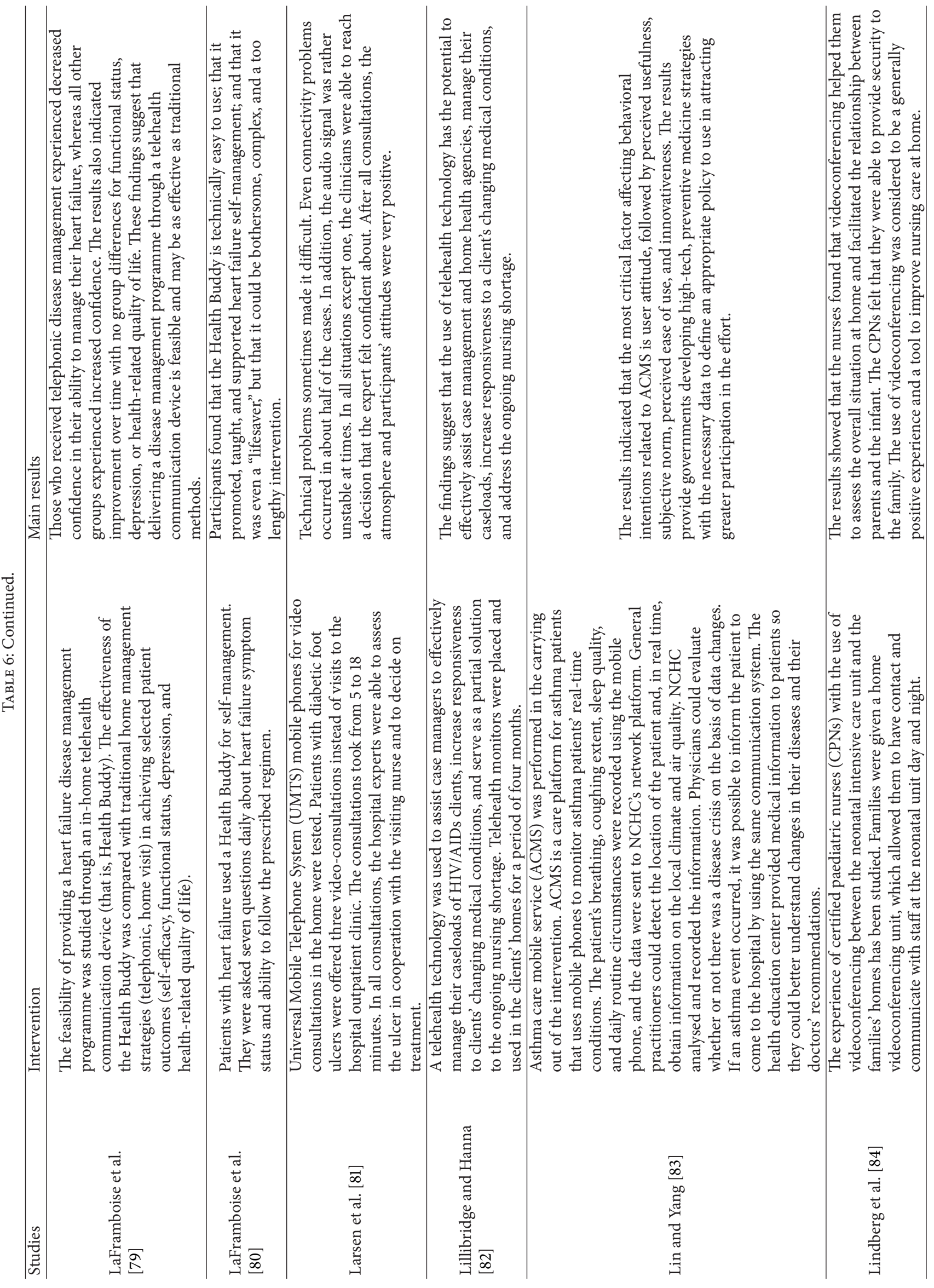




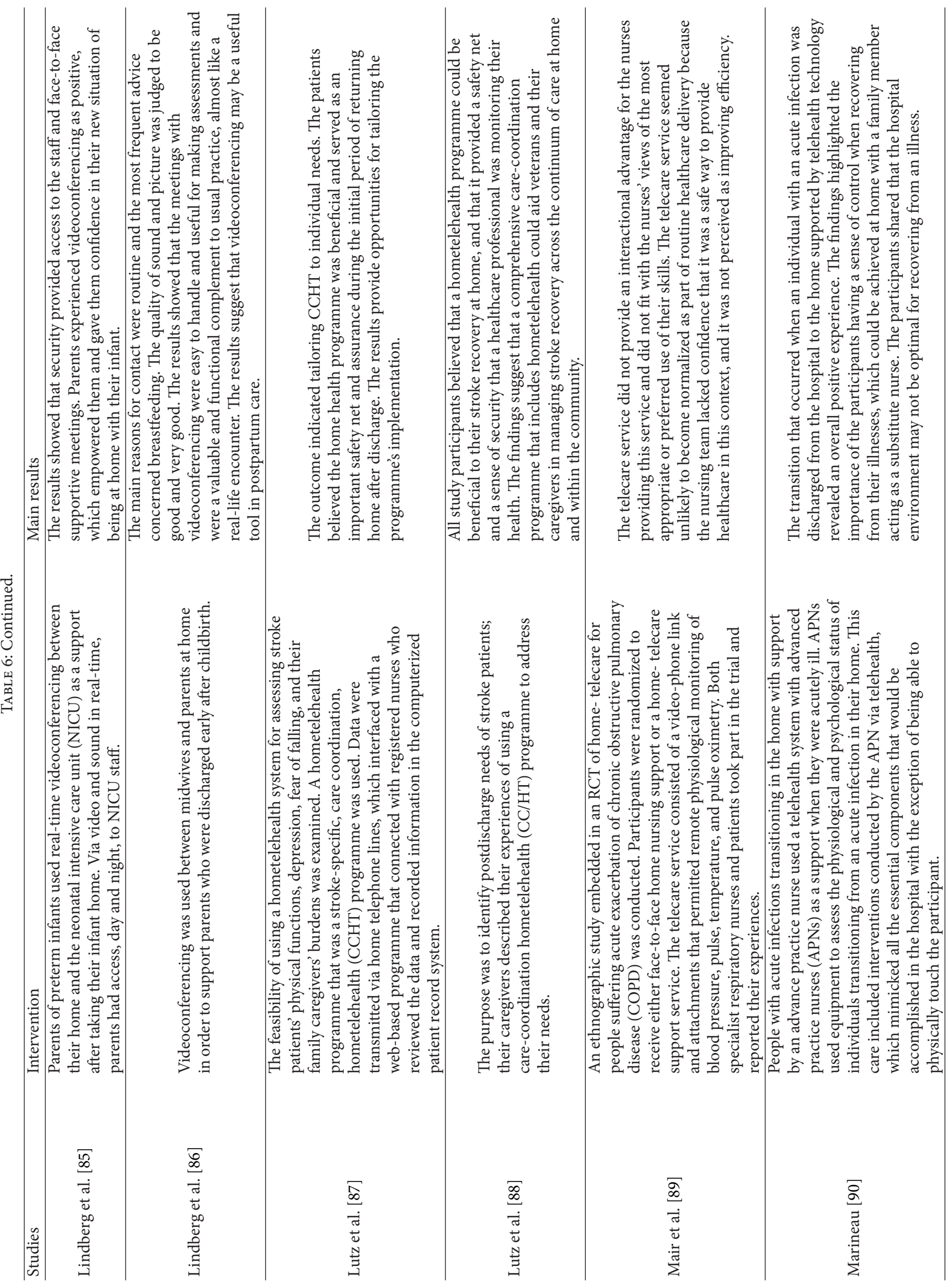




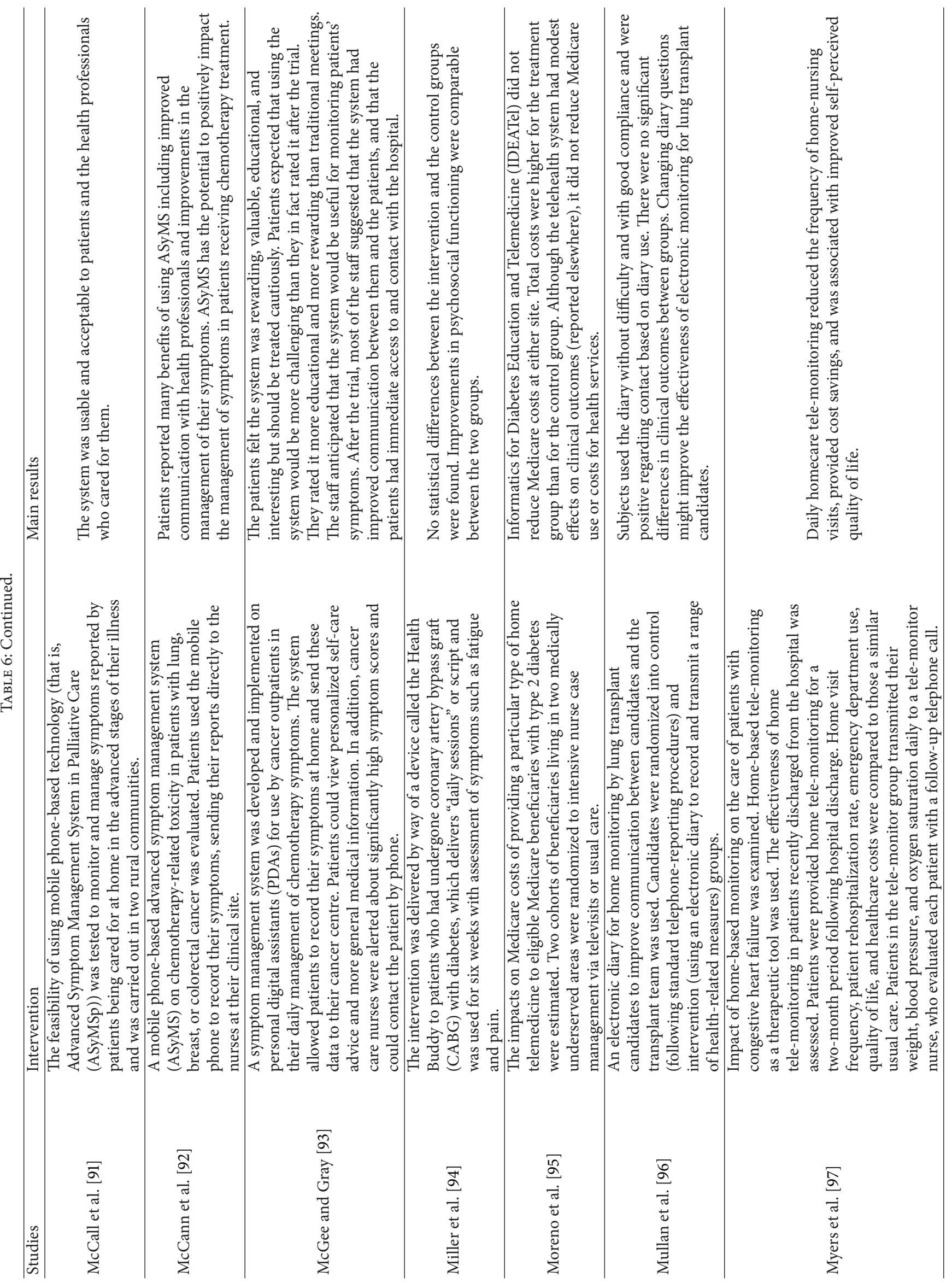




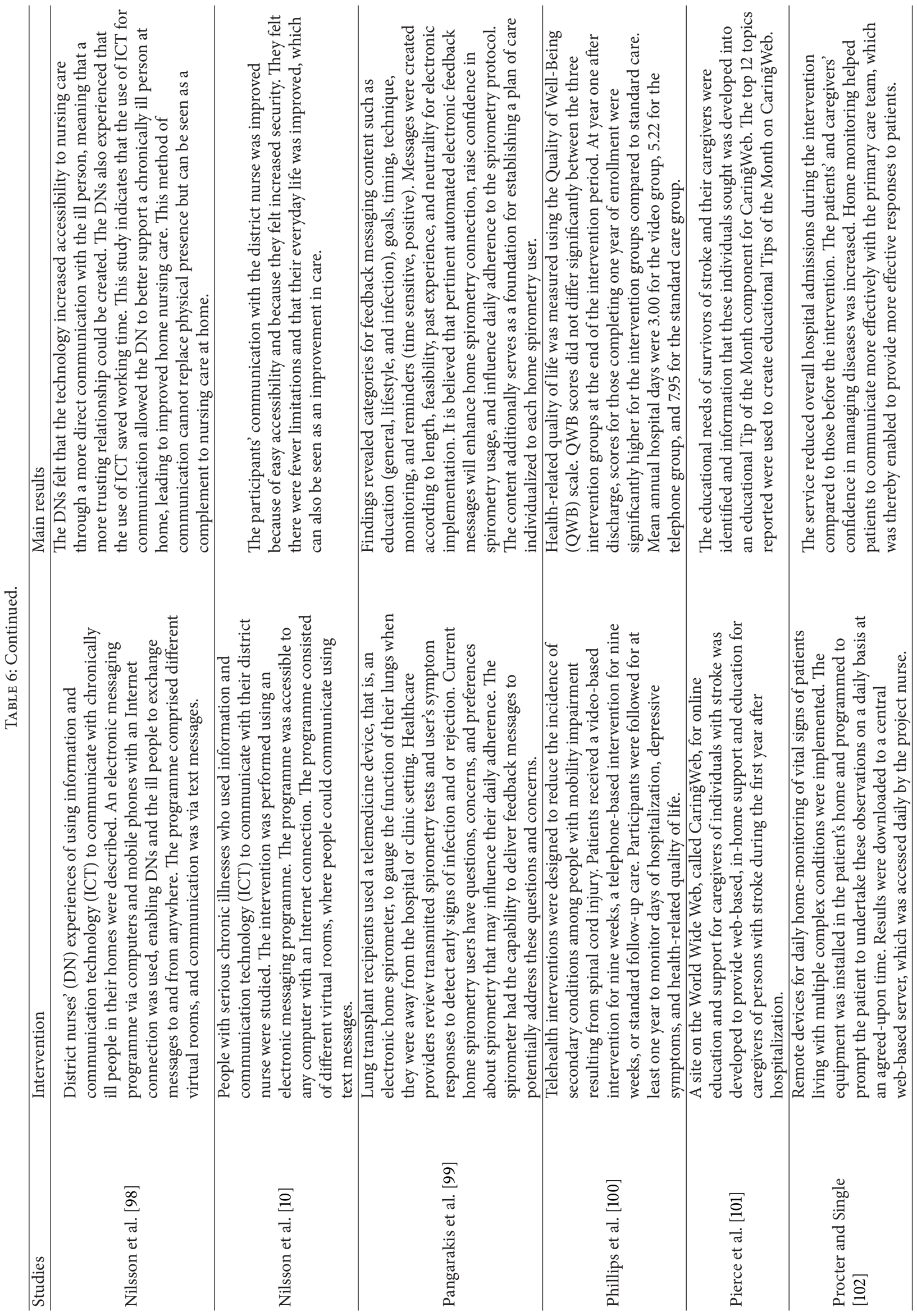




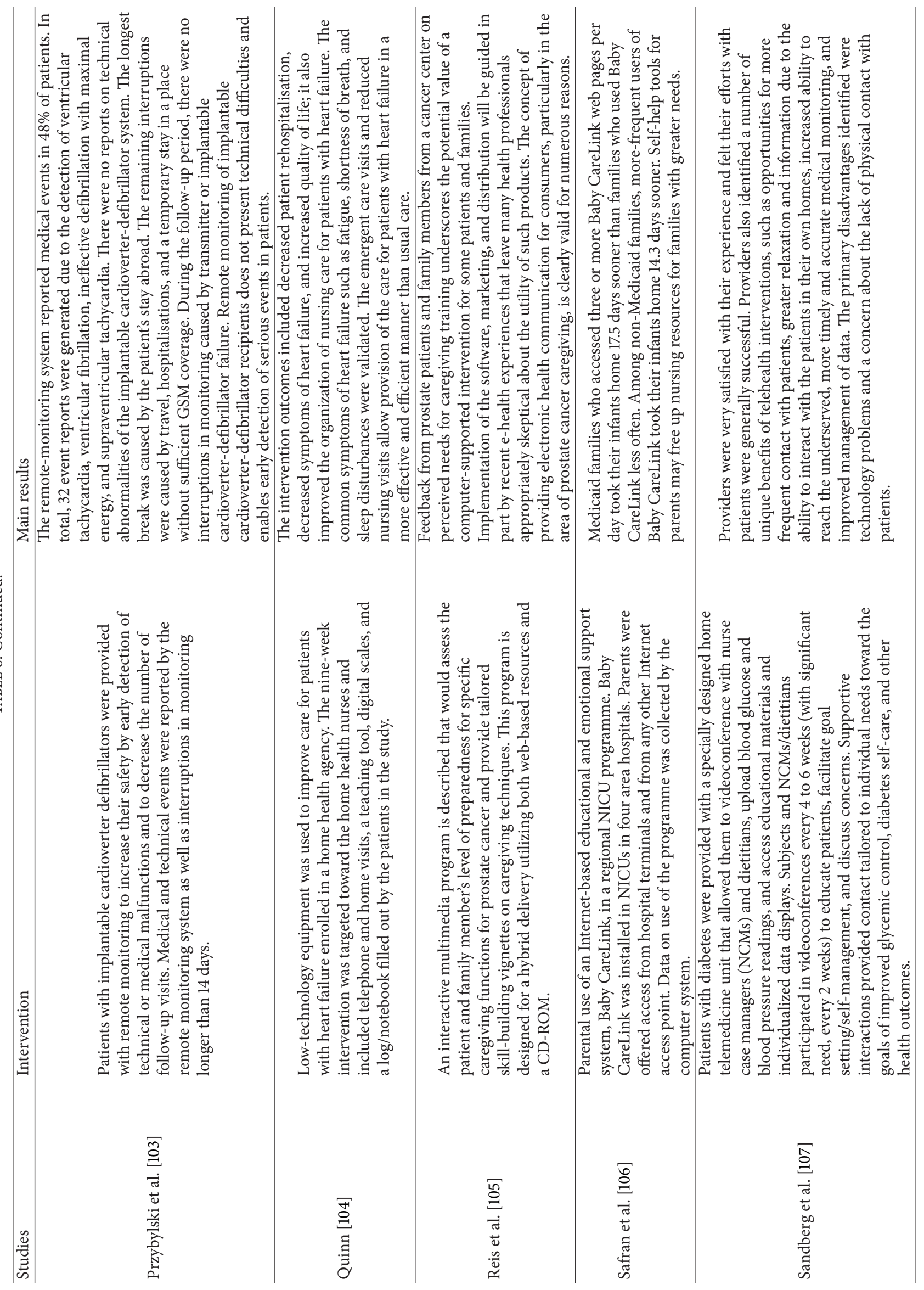




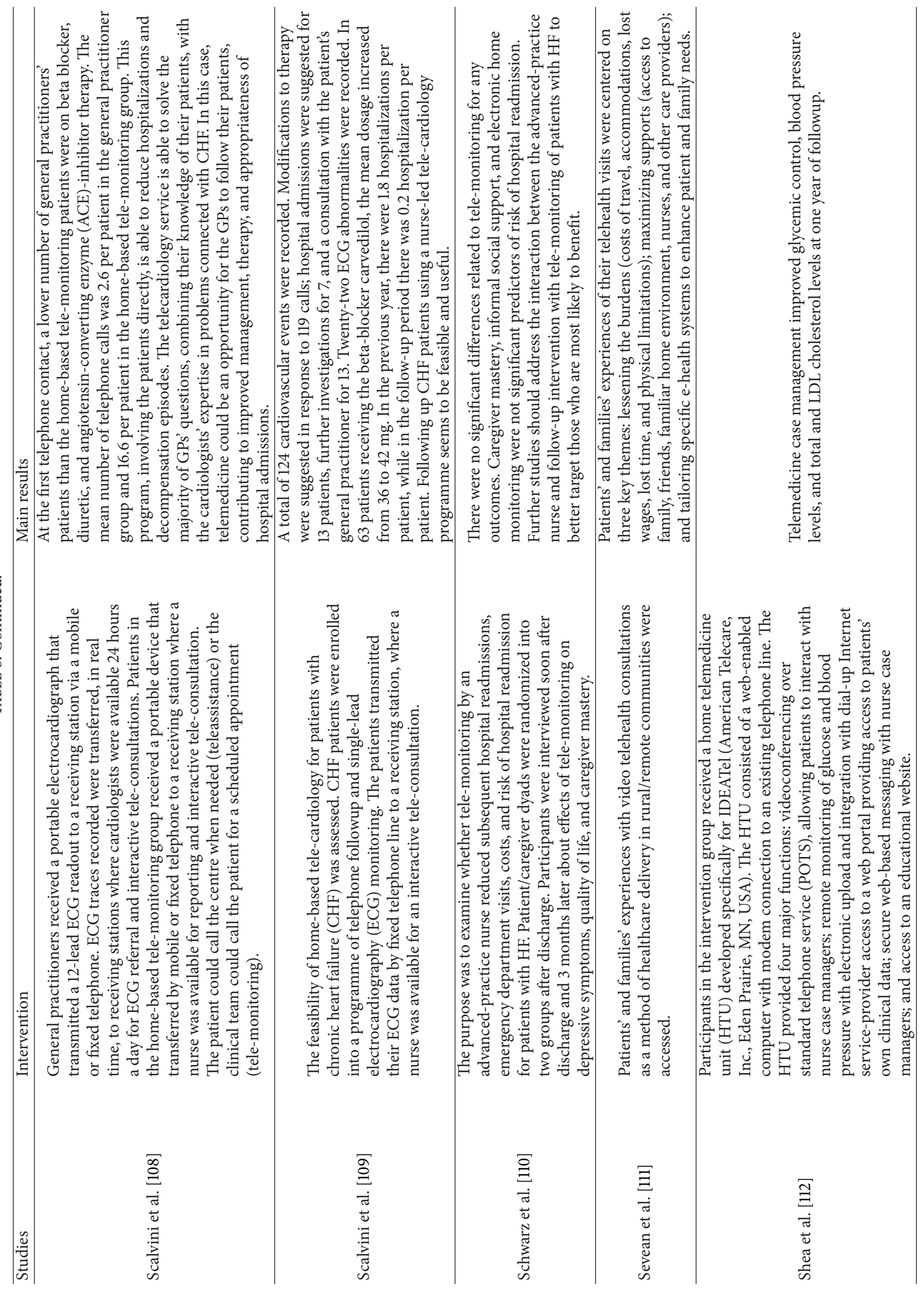




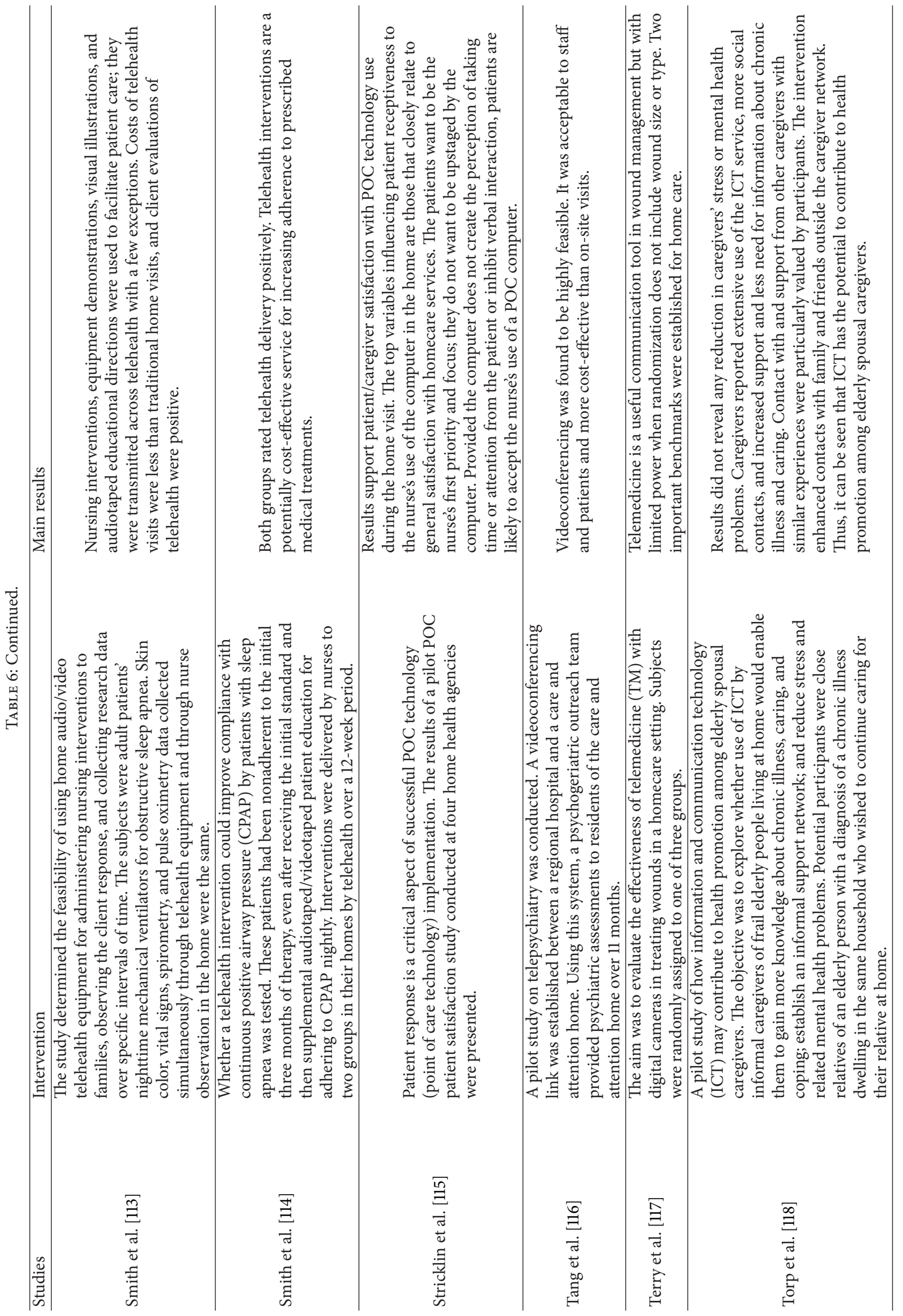




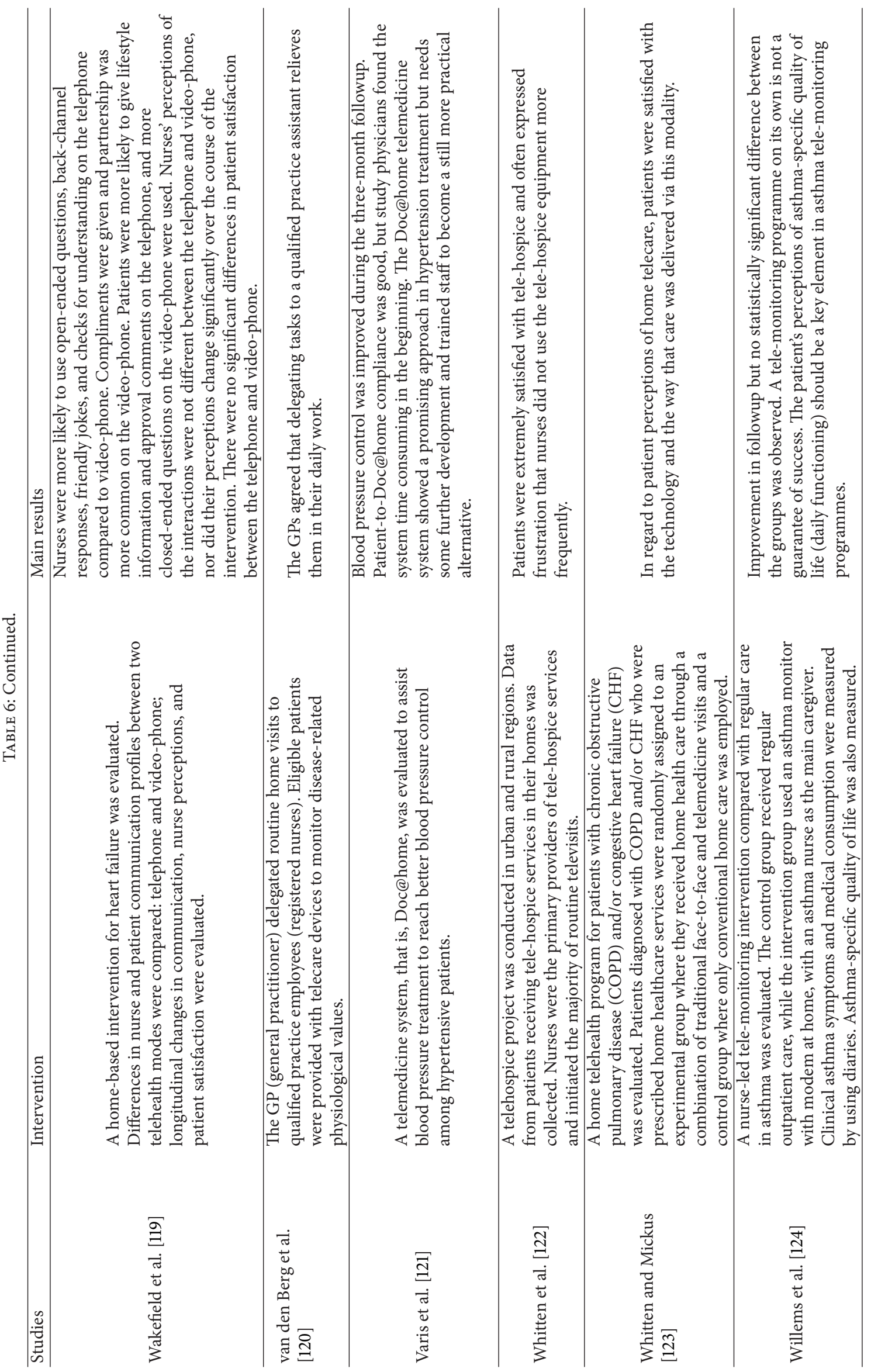




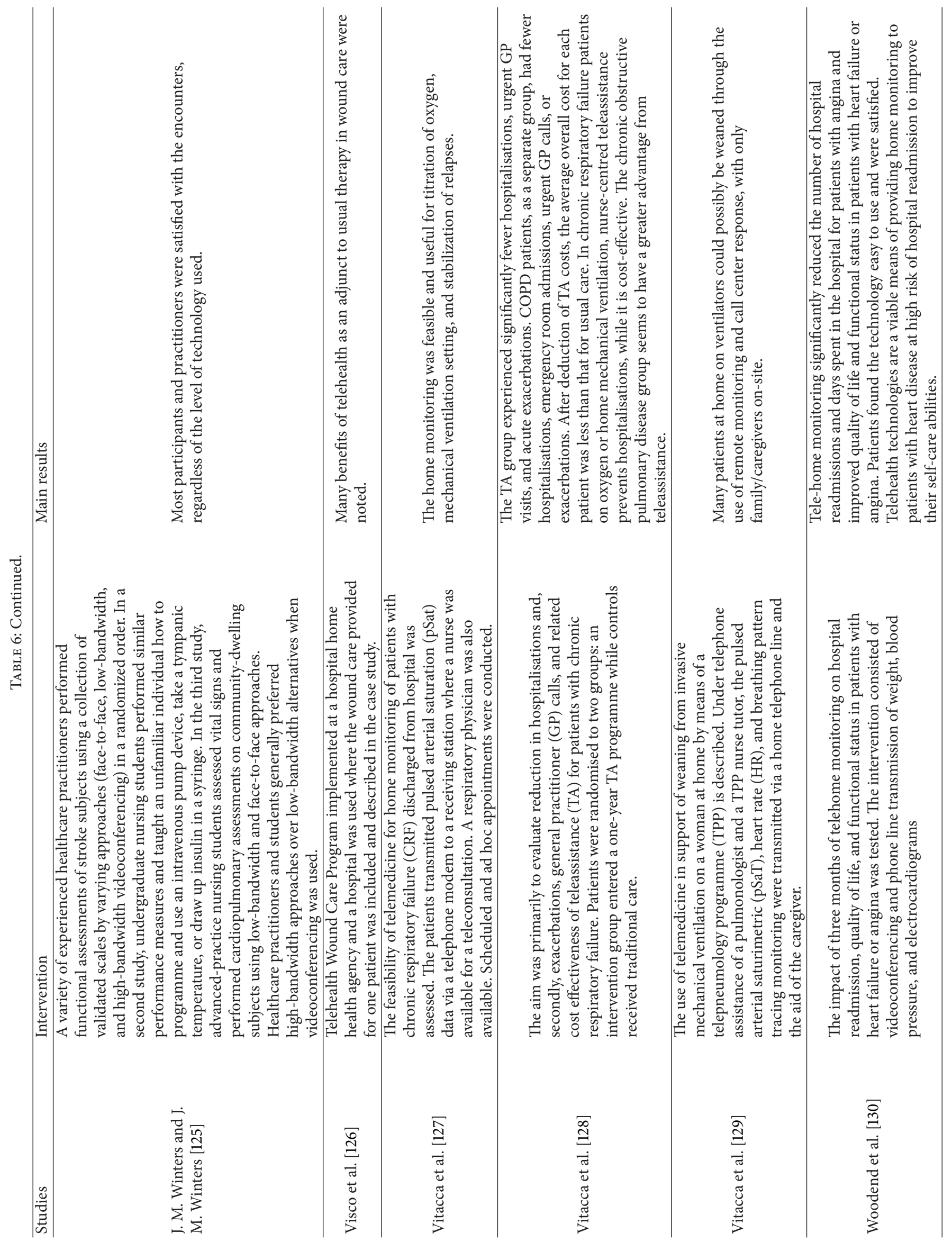




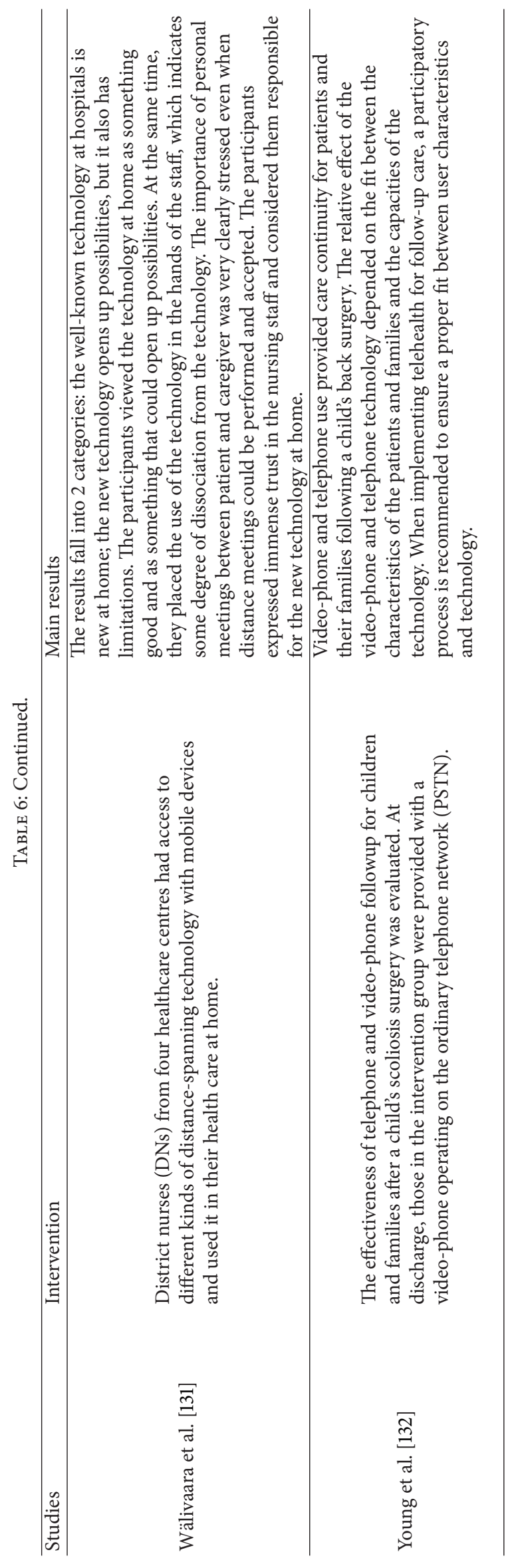


the use of ICT applications, despite that ICT cannot replace a face-to-face encounter but can be used as a complement. Across the literature, outcomes for telehealth-based services are generally comparable to outcomes for services delivered face to face [21]. According to Charlton et al. [133], the style and type of communication the healthcare professional uses influence care outcomes. A literature review [134] shows that patients with possibilities of being cared for and using telecare at home preferred a combination of telecare and traditional healthcare delivery. Therefore, ICT applications must be used as an adjunct and not as replacements for standard care; otherwise, the positive results might not be replicated [135]. Many patients prefer being involved and participating in decision making regarding the care they will receive. Despite this, caring programs will be developed without caregiver's participation [136].

5.1. Methodological Considerations. The strength of this review is the broad literature search that finally resulted in 107 studies. The literature search was systematically conducted using selected databases based on relevant search terms. Even though the database search was done with assistance from a librarian expert in that field, it is possible that some study might have been missed. To get the latest published studies, a search alert was created. A limitation of this review may be that relevant studies might have been missed because of the selection of the English language. During the selection process, a quality appraisal was conducted; thereby, the scientific quality of the included studies could be ensured. The studies included have a great variation in study designs. Therefore, it is not possible to integrate the results and give a more specific summary in this review. However, this was not the intention as the aim was broad; we wanted to find numerous studies for being able to present the state of the art in this field of research.

\section{Conclusion}

The use of ICT applications in home care is an expanding research area, with a variety of ICT applications used to increase access to home care. The result shows that ICT in home care is mostly used as a tool for communication between healthcare professionals and patients or family members. Healthcare professionals can, based on this result, advantageously use ICT applications in home care as a tool to support people living with chronic illnesses gaining control of their illness that promotes self-care. However, a great number of the included studies were performed as pilot studies. For being able to evaluate the effects of ICT applications in home care, more extensive longitudinal studies are needed. To understand more about how ICT can be adjusted to home care, multidisciplinary and qualitative studies are needed from the perspective of the patient and their close relatives.

\section{Conflict of Interests}

The authors claim that there are no competing financial interests.

\section{Acknowledgment}

The authors are grateful to Lotta Frank, librarian at Luleå University Library LRC, Luleå University of Technology, for valuable help with the systematic literature search.

\section{References}

[1] A. Haahr, M. Kirkevold, E. Hall, and K. Østergaard, "Living with advanced Parkinson's disease: a constant struggle with unpredictability," Journal of Advanced Nursing, vol. 67, no. 2, pp. 408-411, 2011.

[2] K. Roback and A. Herzog, "Home informatics in healthcare: assessment guidelines to keep up quality of care and avoid adverse effects," Technology and Health Care, vol. 11, no. 3, pp. 195-206, 2003.

[3] M. Öhman, S. Söderberg, and B. Lundman, "Hovering between suffering and enduring: the meaning of living with chronic illness," Qualitative Health Research, vol. 13, no. 4, pp. 528-524, 2003.

[4] G. Demiris, "The diffusion of virtual communities in health care: concepts and challenges," Patient Education and Counseling, vol. 62, no. 2, pp. 178-188, 2006.

[5] S. Koch and M. Hägglund, "Health informatics and the delivery of care to older people," Maturitas, vol. 63, no. 3, pp. 195-199, 2009.

[6] European Commision, "What is eHealth? ICT for health," Europe's Information Society, 2012, http://ec.europa.eu/information_society/activities/health/whatis_ehealth/index_en.htm.

[7] S. Koch, "Home telehealth: current state and future trends," International Journal of Medical Informatics, vol. 75, no. 8, pp. 565-576, 2006.

[8] WHO, "eHealth for health-care delivery", 2005, http://www .who.int/eht/eHealthHCD/en/index.html.

[9] S. M. Finkelstein, S. M. Speedie, G. Demiris, M. Veen, J. M. Lundgren, and S. Potthoff, "Telehomecare: quality, perception, satisfaction," Telemedicine and e-Health, vol. 10, no. 2, pp. 122128, 2004.

[10] C. Nilsson, M. Öhman, and S. Söderberg, "Information and communication technology in supporting people with serious chronic illness living at home-an intervention study," Journal of Telemedicine and Telecare, vol. 12, no. 4, pp. 198-202, 2006.

[11] A. DiCenso, G. Guyatt, and D. Ciliska, Evidence-Based Nursing: A Guide to Clinical Practice, Elsevier Mosby, St. Louis, Mo, USA, 2005.

[12] SBU (Swedish Council on Technology Assessment in Health Care), "Literature searching and evidence interpretation for assessing health care practices," SBU Report no. 119E, Author, Stockholm, Sweden, 1993.

[13] SBU (Swedish Council on Technology Assessment in Health Care), "Treatment with neuroleptics," SBU Report no. 113, Author, Stockholm, Sweden, 1997.

[14] SBU (Swedish Council on Technology Assessment in Health Care), "Treating asthma and COPD. A systematic review," SBU Report vol. 151, Author, Stockholm, Sweden, 2000.

[15] A. Willman, P. Stoltz, and C. Bahtsevani, Evidence Besed Nursing-A Bridge between Research and Clinical Work, Studentlitteratur, Lund, Sweden, 2006.

[16] C. Bahtsevani, G. Udén, and A. Willman, "Outcomes of evidence-based clinical practice guidelines: a systematic 
review," International Journal of Technology Assessment in Health Care, vol. 20, no. 4, pp. 427-433, 2004.

[17] M. Annersten and A. Willman, "Performing subcutaneous injections: a literature review," Worldviews on Evidence-Based Nursing, vol. 2, no. 3, pp. 122-130, 2005.

[18] M. Tärnhuvud, C. Wändel, and A. Willman, "Nursing interventions to improve the health of men with prostate cancer undergoing radiotherapy: a review," European Journal of Oncology Nursing, vol. 11, no. 4, pp. 328-339, 2007.

[19] Kairos future, "The data explosion and the future of health. What every decision-maker in the health and healthcare industries need to know about the coming revolution," Tech. Rep., Stockholm, Sweden, 2012.

[20] H. J. Liss, R. L. Glueckauf, and E. P. Ecklund-Johnson, "Research on telehealth and chronic medical conditions: critical review, key issues, and future directions," Rehabilitation Psychology, vol. 47, no. 1, pp. 8-30, 2002.

[21] A. F. Sato, L. M. Clifford, A. H. Silverman, and W. H. Davies, "Cognitive-behavioral interventions via telehealth: applications to pediatric functional abdominal pain," Children's Health Care, vol. 38, no. 1, pp. 1-22, 2009.

[22] J. Mitchell, "From telehealth to ehealth: the unstoppable rise of ehealth," Tech. Rep., John Mitchell \& Associates for the Federal Australian Department of Communications, Information Technology and the Arts (DOCITA), Canberra, Australia, 1999.

[23] J. E. Bardram, C. Bossen, and A. Thomsen, "Designing for transformations in collaboration: a study of the deployment of homecare technology," in Proceedings of the International ACM SIGGROUP Conference on Supporting Group Work (GROUP '05), pp. 294-303, November 2005.

[24] S. Koch, "Healthy ageing supported by technology-a crossdisciplinary research challenge," Informatics for Health and Social Care, vol. 35, no. 3-4, pp. 81-91, 2010.

[25] S. Koch, M. Marschollek, K. H. Wolf, M. Plischke, and R. Haux, "On health-enabling and ambient-assistive technologies-what has been achieved and where do we have to go?" Methods of Information in Medicine, vol. 48, no. 1, pp. 29-37, 2009.

[26] A. Venter, R. Burns, M. Hefford, and N. Ehrenberg, "Results of a telehealth-enabled chronic care management service to support people with long-term conditions at home," Journal of Telemedicine and Telecare, vol. 18, pp. 172-175, 2012.

[27] J. A. DePalma, "Telehealth in the community: a research update," Home Health Care Management and Practice, vol. 21, no. 3, pp. 205-207, 2009.

[28] H. Agrell, S. Dahlberg, and A. F. Jerant, "Patients' perceptions regarding home telecare," Telemedicine Journal and e-Health, vol. 6 , no. 4, pp. 409-415, 2000.

[29] J. Ameen, A. M. Coll, and M. Peters, "Impact of tele-advice on community nurses' knowledge of venous leg ulcer care," Journal of Advanced Nursing, vol. 50, no. 6, pp. 583-594, 2005.

[30] A. Arnaert and L. Delesie, "Effectiveness of video-telephone nursing care for the homebound elderly," Canadian Journal of Nursing Research, vol. 39, no. 1, pp. 20-36, 2007.

[31] A. Arnaert, J. Klooster, and V. Chow, "Attitudes towards videotelephones: an exploratory study of older adults with depression," Journal of Gerontological Nursing, vol. 33, no. 9, pp. 5-13, 2007.

[32] N. T. Artinian, O. G. M. Washington, and T. N. Templin, "Effects of home telemonitoring and community-based monitoring on blood pressure control in urban African Americans: a pilot study," Heart and Lung, vol. 30, no. 3, pp. 191-199, 2001.
[33] C. A. Baer, C. M. Williams, L. Vickers, and J. C. Kvedar, "A pilot study of specialized nursing care for home health patients," Journal of Telemedicine and Telecare, vol. 10, no. 6, pp. 342-345, 2004.

[34] S. Barnason, L. Zimmerman, J. Nieveen, and M. Hertzog, "Impact of a telehealth intervention to augment home health care on functional and recovery outcomes of elderly patients undergoing coronary artery bypass grafting," Heart and Lung, vol. 35, no. 4, pp. 225-233, 2006.

[35] S. Barnason, L. Zimmerman, J. Nieveen, M. Schmaderer, B. Carranza, and S. Reilly, "Impact of a home communication intervention for coronary artery bypass graft patients with ischemic heart failure on self-efficacy, coronary disease risk factor modification, and functioning," Heart and Lung, vol. 32, no. 3, pp. 147-158, 2003.

[36] D. Benatar, M. Bondmass, J. Ghitelman, and B. Avitall, "Outcomes of chronic heart failure," Archives of Internal Medicine, vol. 163, no. 3, pp. 347-352, 2003.

[37] R. M. Bendixen, C. E. Levy, E. S. Olive, R. F. Kobb, and W. C. Mann, "Cost effectiveness of a telerehabilitation program to support chronically ill and disabled elders in their homes," Telemedicine and e-Health, vol. 15, no. 1, pp. 31-38, 2009.

[38] S. K. Bohnenkamp, P. McDonald, A. M. Lopez, E. Krupinski, and A. Blackett, "Traditional versus telenursing outpatient management of patients with cancer with new ostomies," Oncology Nursing Forum, vol. 31, no. 5, pp. 1005-1010, 2004.

[39] K. H. Bowles and K. H. Dansky, "Teaching self-management of diabetes via telehomecare," Home Healthcare Nurse, vol. 20, no. 1, pp. 36-42, 2002.

[40] K. H. Bowles, D. E. Holland, and D. A. Horowitz, "A comparison of in-person home care, home care with telephone contact and home care with telemonitoring for disease management," Journal of Telemedicine and Telecare, vol. 15, no. 7, pp. 344-350, 2009.

[41] P. F. Brennan, G. Casper, S. Kossman, and L. Burke, "HeartCareII: home care support for patients with chronic cardiac disease," Studies in Health Technology and Informatics, vol. 129, part 2, pp. 988-992, 2007.

[42] K. Buckley, B. Tran, J. Agazio, and E. Wuertz, "A communitybased telehealth programme for elderly low-income African Americans," Journal on Information Technology in Healthcare, vol. 6, no. 6, pp. 400-412, 2008.

[43] K. M. Buckley, L. K. Adelson, and J. G. Agazio, "Reducing the risks of wound consultation: adding digital images to verbal reports," Journal of Wound, Ostomy and Continence Nursing, vol. 36, no. 2, pp. 163-170, 2009.

[44] K. M. Buckley, B. Q. Tran, and C. M. Prandoni, "Receptiveness, use and acceptance of telehealth by caregivers of stroke patients in the home," Online Journal of Issues in Nursing, vol. 9, no. 3, p. 9, 2004

[45] L. Cardozo and J. Steinberg, "Telemedicine for recently discharged older patients," Telemedicine and e-Health, vol. 16, no. 1, pp. 49-55, 2010.

[46] Y. M. Chae, J. H. Lee, S. H. Ho, H. J. Kim, K. H. Jun, and J. K. Won, "Patient satisfaction with telemedicine in home health services for the elderly," International Journal of Medical Informatics, vol. 61, no. 2-3, pp. 167-173, 2001.

[47] M. Chambers and S. Connor, "Technology as an aid to coping with caring: a usability evaluation of a telematics intervention," Studies in Health Technology and Informatics, vol. 84, part 2, pp. 1130-1134, 2001. 
[48] M. Chambers and S. L. Connor, "User-friendly technology to help family carers cope," Journal of Advanced Nursing, vol. 40, no. 5, pp. 568-577, 2002.

[49] K. Chang, R. Davis, J. Birt, P. Castelluccio, P. Woodbridge, and D. Marrero, "Nurse practitioner-based diabetes care management: impact of telehealth or telephone intervention on glycemic control," Disease Management and Health Outcomes, vol. 15, no. 6, pp. 377-385, 2007.

[50] J. G. F. Cleland, A. A. Louis, A. S. Rigby, U. Janssens, and A. H. M. M. Balk, "Noninvasive home telemonitoring for patients with heart failure at high risk of recurrent admission and death: the Trans-European Network-Home-Care Management System (TEN-HMS) study," Journal of the American College of Cardiology, vol. 45, no. 10, pp. 1654-1664, 2005.

[51] J. Clemensen, S. B. Larsen, M. Kirkevold, and N. Ejskjaer, "Telemedical teamwork between home and hospital: a synergetic triangle emerges," Studies in Health Technology and Informatics, vol. 130, pp. 81-89, 2007.

[52] S. Dang, N. Remon, J. Harris et al., "Care coordination assisted by technology for multiethnic caregivers of persons with dementia: a pilot clinical demonstration project on caregiver burden and depression," Journal of Telemedicine and Telecare, vol. 14, no. 8, pp. 443-447, 2008.

[53] K. Dansky and J. Vasey, "Managing heart failure patients after formal homecare," Telemedicine and e-Health, vol. 15, no. 10, pp. 983-991, 2009.

[54] K. H. Dansky, J. Vasey, and K. Bowles, "Impact of telehealth on clinical outcomes in patients with heart failure," Clinical Nursing Research, vol. 17, no. 3, pp. 182-199, 2008.

[55] K. H. Dansky, J. Vasey, and K. Bowles, "Use of telehealth by older adults to manage heart failure," Research in Gerontological Nursing, vol. 1, no. 1, pp. 25-32, 2008.

[56] K. H. Dansky, B. Yant, D. Jenkins, and C. Dellasega, "Qualitative analysis of telehomecare nursing activities," Journal of Nursing Administration, vol. 33, no. 7-8, pp. 372-375, 2003.

[57] A. Darkins, P. Ryan, R. Kobb et al., "Care coordination/home telehealth: the systematic implementation of health informatics, home telehealth, and disease management to support the care of veteran patients with chronic conditions," Telemedicine and e-Health, vol. 14, no. 10, pp. 1118-1126, 2008.

[58] S. de Lusignan, S. Wells, P. Johnson, K. Meredith, and E. Leatham, "Compliance and effectiveness of 1 year's home telemonitoring. The report of a pilot study of patients with chronic heart failure," European Journal of Heart Failure, vol. 3, no. 6, pp. 723-730, 2001.

[59] J. L. DelliFraine, K. H. Dansky, and J. S. Rumberger, "The use of knowledge management in telemedicine and perceived effects on patient care activities," International Journal of Healthcare Technology and Management, vol. 10, no. 3, pp. 196-209, 2009.

[60] G. Demiris, S. M. Speedie, and S. Finkelstein, "Change of patients' perceptions of TeleHomeCare," Telemedicine Journal and e-Health, vol. 7, no. 3, pp. 241-248, 2001.

[61] T. R. Elliott, D. Brossart, J. W. Berry, and P. R. Fine, "Problemsolving training via videoconferencing for family caregivers of persons with spinal cord injuries: a randomized controlled trial," Behaviour Research and Therapy, vol. 46, no. 11, pp. 12201229, 2008.

[62] S. M. Finkelstein, S. M. Speedie, and S. Potthoff, "Home telehealth improves clinical outcomes at lower cost for home healthcare," Telemedicine Journal and e-Health, vol. 12, no. 2, pp. 128-136, 2006.
[63] L. Forbat, R. Maguire, L. McCann, N. Illingworth, and N. Kearney, "The use of technology in cancer care: applying Foucault's ideas to explore the changing dynamics of power in health care," Journal of Advanced Nursing, vol. 65, no. 2, pp. 306$315,2009$.

[64] J. E. Gray, C. Safran, R. B. Davis et al., "Baby CareLink: using the internet and telemedicine to improve care for high-risk infants," Pediatrics, vol. 106, no. 6, pp. 1318-1324, 2000.

[65] C. Guilfoyle, L. Perry, B. Lord, K. Buckle, J. Mathews, and R. Wootton, "Developing a protocol for the use of telenursing in community health in Australia," Journal of Telemedicine and Telecare, vol. 8, supplement 2, pp. 33-36, 2002.

[66] R. P. Hauber and M. L. Jones, “Telerehabilitation support for families at home caring for individuals in prolonged states of reduced consciousness," Journal of Head Trauma Rehabilitation, vol. 17, no. 6, pp. 535-541, 2002.

[67] Y. Hirakawa, Y. Masuda, K. Uemura, M. Kuzuya, and A. Iguchi, "Effect of long-term care insurance on communication/recording tasks for in-home nursing care services," Archives of Gerontology and Geriatrics, vol. 38, no. 2, pp. 101-113, 2004.

[68] R. Hofmann-Wellenhof, W. Salmhofer, B. Binder, A. Okcu, H. Kerl, and H. P. Soyer, "Feasibility and acceptance of telemedicine for wound care in patients with chronic leg ulcers," Journal of Telemedicine and Telecare, vol. 12, supplement 1, pp. 15-17, 2006.

[69] K. Horton, "The use of telecare for people with chronic obstructive pulmonary disease: implications for management," Journal of Nursing Management, vol. 16, no. 2, pp. 173-180, 2008.

[70] M. Huddleston and R. Kobb, "Emerging technology for at-risk chronically ill veterans," Journal for Healthcare Quality, vol. 26, no. 6, pp. 12-24, 2004.

[71] R. L. Jenkins and M. McSweeney, "Assessing elderly patients with congestive heart failure via in-home interactive telecommunication," Journal of Gerontological Nursing, vol. 27, no. 1, pp. 21-27, 2001.

[72] A. F. Jerant, R. Azari, C. Martinez, and T. S. Nesbitt, "A randomized trial of telenursing to reduce hospitalization for heart failure: patient-centered outcomes and nursing indicators," Home Health Care Services Quarterly, vol. 22, no. 1, pp. $1-20,2003$.

[73] A. F. Jerant, R. Azari, and T. S. Nesbitt, "Reducing the cost of frequent hospital admissions for congestive heart failure: a randomized trial of a home telecare intervention," Medical Care, vol. 39, no. 11, pp. 1234-1245, 2001.

[74] T. Kawaguchi, M. Azuma, and K. Ohta, "Development of a telenursing system for patients with chronic conditions," Journal of Telemedicine and Telecare, vol. 10, no. 4, pp. 239-244, 2004.

[75] N. Kearney, L. Kidd, M. Miller et al., "Utilising handheld computers to monitor and support patients receiving chemotherapy: results of a UK-based feasibility study," Supportive Care in Cancer, vol. 14, no. 7, pp. 742-752, 2006.

[76] L. Keaton, L. Pierce, V. Steiner et al., "An E-rehabilitation team helps caregivers deal with stroke," The Internet Journal of Allied Health Sciences and Practice, vol. 2, no. 4, p. 17, 2004.

[77] R. M. Kleinpell and B. Avitall, "Integrating telehealth as a strategy for patient management after discharge for cardiac surgery: results of a pilot study," Journal of Cardiovascular Nursing, vol. 22, no. 1, pp. 38-42, 2007. 
[78] L. Kobza and A. Scheurich, "The impact of telemedicine on outcomes of chronic wounds in the home care setting," Ostomy/Wound Management, vol. 46, no. 10, pp. 48-53, 2000.

[79] L. M. LaFramboise, C. M. Todero, L. Zimmerman, and S. Agrawal, "Comparison of Health Buddy with traditional approaches to heart failure management," Family \& Community Health, vol. 26, no. 4, pp. 275-288, 2003.

[80] L. M. LaFramboise, J. Woster, A. Yager, and B. C. Yates, "A technological life buoy: patient perceptions of the Health Buddy," Journal of Cardiovascular Nursing, vol. 24, no. 3, pp. 216-224, 2009.

[81] S. B. Larsen, J. Clemensen, and N. Ejskjaer, "A feasibility study of UMTS mobile phones for supporting nurses doing home visits to patients with diabetic foot ulcers," Journal of Telemedicine and Telecare, vol. 12, no. 7, pp. 358-362, 2006.

[82] J. Lillibridge and B. Hanna, "Using telehealth to deliver nursing case management services to HIV/AIDS clients," Online Journal of Issues in Nursing, vol. 14, no. 1, p. 9, 2009.

[83] S. P. Lin and H. Y. Yang, "Exploring key factors in the choice of ehealth using an asthma care mobile service model," Telemedicine and e-Health, vol. 15, no. 9, pp. 884-890, 2009.

[84] B. Lindberg, K. Axelsson, and K. Öhrling, "Experience with videoconferencing between a neonatal unit and the families' home from the perspective of certified paediatric nurses," Journal of Telemedicine and Telecare, vol. 15, no. 6, pp. 275-280, 2009.

[85] B. Lindberg, K. Axelsson, and K. Öhrling, “Taking care of their baby at home but with nursing staff as support: the use of videoconferencing in providing neonatal support to parents of preterm infants," Journal of Neonatal Nursing, vol. 15, no. 2, pp. 47-55, 2009.

[86] I. Lindberg, K. Öhrling, and K. Christensson, "Midwives' experience of using videoconferencing to support parents who were discharged early after childbirth," Journal of Telemedicine and Telecare, vol. 13, no. 4, pp. 202-205, 2007.

[87] B. J. Lutz, N. R. Chumbler, T. Lyles, N. Hoffman, and R. Kobb, "Testing a home-telehealth programme for US veterans recovering from stroke and their family caregivers," Disability and Rehabilitation, vol. 31, no. 5, pp. 402-409, 2009.

[88] B. J. Lutz, N. R. Chumbler, and K. Roland, "Care coordination/home-telehealth for veterans with stroke and their caregivers: addressing an unmet need," Topics in Stroke Rehabilitation, vol. 14, no. 2, pp. 32-42, 2007.

[89] F. S. Mair, J. Hiscock, and S. C. Beaton, "Understanding factors that inhibit or promote the utilization of telecare in chronic lung disease," Chronic Illness, vol. 4, no. 2, pp. 110-117, 2008.

[90] M. L. Marineau, "Special populations: telehealth advance practice nursing: the lived experiences of individuals with acute infections transitioning in the home," Nursing Forum, vol. 42, no. 4, pp. 196-208, 2007.

[91] K. McCall, J. Keen, K. Farrer et al., "Perceptions of the use of a remote monitoring system in patients receiving palliative care at home," International Journal of Palliative Nursing, vol. 14, no. 9, pp. 426-431, 2008.

[92] L. McCann, R. Maguire, M. Miller, and N. Kearney, "Patients' perceptions and experiences of using a mobile phone-based advanced symptom management system (ASyMS) to monitor and manage chemotherapy related toxicity," European Journal of Cancer Care, vol. 18, no. 2, pp. 156-164, 2009.

[93] M. R. McGee and P. Gray, "A handheld chemotherapy symptom management system: results from a preliminary outpatient field trial,' Health Informatics Journal, vol. 11, no. 4, pp. 243-258, 2005.

[94] C. Miller, L. Zimmerman, S. Barnason, and J. Nieveen, "Impact of an early recovery management intervention on functioning in postoperative coronary artery bypass patients with diabetes," Heart and Lung, vol. 36, no. 6, pp. 418-430, 2007.

[95] L. Moreno, S. B. Dale, A. Y. Chen, and C. A. Magee, "Costs to Medicare of the Informatics for Diabetes Education and Telemedicine (IDEATel) Home Telemedicine demonstration: findings from an independent evaluation," Diabetes Care, vol. 32, no. 7, pp. 1202-1204, 2009.

[96] B. Mullan, M. Snyder, B. Lindgren, S. M. Finkelstein, and M. I. Hertz, "Home monitoring for lung transplant candidates," Progress in Transplantation, vol. 13, no. 3, pp. 176-182, 2003.

[97] S. Myers, W. R. Grant, E. N. Lugn, B. Holbert, and C. J. Kvedar, "Impact of home-based monitoring on the care of patients with congestive heart failure," Home Health Care Management and Practice, vol. 18, no. 6, pp. 444-451, 2006.

[98] C. Nilsson, L. Skär, and S. Söderberg, 'Swedish District Nurses' experiences on the use of information and communication technology for supporting people with serious chronic illness living at home-a case study," Scandinavian Journal of Caring Science, vol. 24, pp. 259-265, 2010.

[99] S. J. Pangarakis, K. Harrington, R. Lindquist, C. PedenMcAlpine, and S. Finkelstein, "Electronic feedback messages for home spirometry lung transplant recipients," Heart and Lung, vol. 37, no. 4, pp. 299-307, 2008.

[100] V. L. Phillips, S. Vesmarovich, R. Hauber, E. Wiggers, and A. Egner, "Telehealth: reaching out to newly injured spinal cord patients," Public Health Reports, vol. 116, supplement 1, pp. 94102, 2001.

[101] L. L. Pierce, G. L. Rupp, B. Hicks, and V. Steiner, "Meeting the educational needs for caregivers and survivors of stroke," Gerontology \& Geriatrics Education, vol. 23, no. 4, pp. 75-90, 2003.

[102] S. Procter and A. Single, "Home telehealthcare: findings from a pilot study in North-east London," British Journal of Healthcare Computing \& Medical Informatics, vol. 23, no. 8, pp. 10-13, 2006.

[103] A. Przybylski, J. Zakrzewska-Koperska, A. Maciag et al., "Technical and practical aspects of remote monitoring of implantable cardioverter-defibrillator patients in Polandpreliminary results," Kardiologia Polska, vol. 67, no. 5, pp. 505511, 2009.

[104] C. Quinn, "Low-technology heart failure care in home health: improving patient outcomes," Home Healthcare Nurse, vol. 24, no. 8, pp. 533-540, 2006.

[105] J. Reis, B. McGinty, and S. Jones, "An e-learning caregiving program for prostate cancer patients and family members," Journal of Medical Systems, vol. 27, no. 1, pp. 1-12, 2003.

[106] C. Safran, G. Pompilio-Weitzner, K. D. Emery, and L. Hampers, "Collaborative approaches to e-health: valuable for users and non-users," Studies in Health Technology and Informatics, vol. 116, pp. 879-884, 2005.

[107] J. Sandberg, P. M. Trief, R. Izquierdo et al., "A qualitative study of the experiences and satisfaction of direct telemedicine providers in diabetes case management," Telemedicine Journal and e-Health, vol. 15, no. 8, pp. 742-750, 2009.

[108] S. Scalvini, E. Zanelli, L. Paletta et al., "Chronic heart failure home-based management with a telecardiology system: a comparison between patients followed by general practitioners and by a cardiology department," Journal of Telemedicine and Telecare, vol. 12, supplement 1, pp. 46-48, 2006. 
[109] S. Scalvini, E. Zanelli, M. Volterrani et al., "A pilot study of nurse-led, home-based telecardiology for patients with chronic heart failure," Journal of Telemedicine and Telecare, vol. 10, no. 2, pp. 113-117, 2004.

[110] K. A. Schwarz, L. C. Mion, D. Hudock, and G. Litman, "Telemonitoring of heart failure patients and their caregivers: a pilot randomized controlled trial," Progress in Cardiovascular Nursing, vol. 23, no. 1, pp. 18-26, 2008.

[111] P. Sevean, S. Dampier, M. Spadoni, S. Strickland, and S. Pilatzke, "Patients and families experiences with video telehealth in rural/remote communities in Northern Canada," Journal of Clinical Nursing, vol. 18, no. 18, pp. 2573-2579, 2009.

[112] S. Shea, R. S. Weinstock, J. A. Teresi et al., "A randomized trial comparing telemedicine case management with usual care in older, ethnically diverse, medically underserved patients with diabetes mellitus: 5 year results of the IDEATel study," Journal of the American Medical Informatics Association, vol. 16, no. 4, pp. 446-456, 2009.

[113] C. E. Smith, J. J. Cha, S. V. Kleinbeck, F. A. Clements, D. Cook, and J. Koehler, "Feasibility of in-home telehealth for conducting nursing research," Clinical Nursing Research, vol. 11, no. 2, pp. 220-233, 2002.

[114] C. E. Smith, E. R. Dauz, F. Clements et al., "Telehealth services to improve nonadherence: a placebo-controlled study," Telemedicine Journal and e-Health, vol. 12, no. 3, pp. 289-296, 2006.

[115] M. L. Stricklin, K. Lowe-Phelps, and R. J. McVey, "Home care patients' responses to point-of-care technology," Home Healthcare Nurse, vol. 19, no. 12, pp. 774-778, 2001.

[116] W. K. Tang, H. Chiu, J. Woo, M. Hjelm, and E. Hui, “Telepsychiatry in psychogeriatric service: a pilot study," International Journal of Geriatric Psychiatry, vol. 16, no. 1, pp. 88-93, 2001.

[117] M. Terry, L. S. Halstead, P. O'Hare et al., "Feasibility study of home care wound management using telemedicine," Advances in Skin \& Wound Care, vol. 22, no. 8, pp. 358-364, 2009.

[118] S. Torp, E. Hanson, S. Hauge, I. Ulstein, and L. Magnusson, "A pilot study of how information and communication technology may contribute to health promotion among elderly spousal carers in Norway," Health and Social Care in the Community, vol. 16, no. 1, pp. 75-85, 2008.

[119] B. J. Wakefield, C. L. Bylund, J. E. Holman et al., "Nurse and patient communication profiles in a home-based telehealth intervention for heart failure management," Patient Education and Counseling, vol. 71, no. 2, pp. 285-292, 2008.

[120] N. van den Berg, T. Fiß, C. Meinke, R. Heymann, S. Scriba, and W. Hoffmann, "GP-support by means of AGnES-practice assistants and the use of telecare devices in a sparsely populated region in Northern Germany proof of concept," BMC Family Practice, vol. 10, article 44, 2009.

[121] J. Varis, S. Karjalainen, K. Korhonen, M. Viigimaa, K. Port, and I. Kantola, "Experiences of telemedicine-aided hypertension control in the follow-up of Finnish hypertensive patients," Telemedicine Journal and e-Health, vol. 15, no. 8, pp. 764-769, 2009.

[122] P. Whitten, G. Doolittle, and M. Mackert, "Telehospice in Michigan: use and patient acceptance," American Journal of Hospice and Palliative Care, vol. 21, no. 3, pp. 191-195, 2004.

[123] P. Whitten and M. Mickus, "Home telecare for COPD/CHF patients: outcomes and perceptions," Journal of Telemedicine and Telecare, vol. 13, no. 2, pp. 69-73, 2007.

[124] D. C. M. Willems, M. A. Joore, J. J. E. Hendriks, F. H. M. Nieman, J. L. Severens, and E. F. M. Wouters, "The effectiveness of nurse-led telemonitoring of asthma: results of a randomized controlled trial," Journal of Evaluation in Clinical Practice, vol. 14, no. 4, pp. 600-609, 2008.

[125] J. M. Winters and J. M. Winters, "Videoconferencing and telehealth technologies can provide a reliable approach to remote assessment and teaching without compromising quality," Journal of Cardiovascular Nursing, vol. 22, no. 1, pp. 51-57, 2007.

[126] D. C. Visco, T. Shalley, S. J. Wren et al., "Use of telehealth for chronic wound care: a case study," Journal of Wound, Ostomy and Continence Nursing, vol. 28, no. 2, pp. 89-95, 2001.

[127] M. Vitacca, G. Assoni, P. Pizzocaro et al., "A pilot study of nurseled, home monitoring for patients with chronic respiratory failure and with mechanical ventilation assistance," Journal of Telemedicine and Telecare, vol. 12, no. 7, pp. 337-342, 2006.

[128] M. Vitacca, L. Bianchi, A. Guerra et al., "Tele-assistance in chronic respiratory failure patients: a randomised clinical trial," European Respiratory Journal, vol. 33, no. 2, pp. 411-418, 2009.

[129] M. Vitacca, A. Guerra, G. Assoni et al., "Weaning from mechanical ventilation followed at home with the aid of a telemedicine program," Telemedicine Journal and e-Health, vol. 13, no. 4, pp. 445-449, 2007.

[130] A. K. Woodend, H. Sherrard, M. Fraser, L. Stuewe, T. Cheung, and C. Struthers, "Telehome monitoring in patients with cardiac disease who are at high risk of readmission," Heart and Lung, vol. 37, no. 1, pp. 36-45, 2008.

[131] B. M. Wälivaara, S. Andersson, and K. Axelsson, "Views on technology among people in need of health care at home," International Journal of Circumpolar Health, vol. 68, no. 2, pp. 158-169, 2009.

[132] L. Young, H. Siden, and S. Tredwell, "Post-surgical telehealth support for children and family care-givers," Journal of Telemedicine and Telecare, vol. 13, no. 1, pp. 15-19, 2007.

[133] C. R. Charlton, K. S. Dearing, J. A. Berry, and M. J. Johnson, "Nurse practitioners'communication styles and their impact on patient outcomes: an integrated literature review," Journal of the American Academy of Nurse Practitioners, vol. 20, pp. 382-388, 2008.

[134] T. Botsis and G. Hartvigsen, "Current status and future perspectives in telecare for elderly people suffering from chronic diseases," Journal of Telemedicine and Telecare, vol. 14, no. 4, pp. 195-203, 2008.

[135] T. L. Williams, C. R. May, and A. Esmail, "Limitations of patient satisfaction studies in telehealthcare: a systematic review of the literature," Telemedicine Journal and e-Health, vol. 7, no. 4, pp. 293-316, 2001.

[136] F. Ducharme, L. Beaudet, A. Legault, M.-J. Kergoat, L. Lévesque, and C. Caron, "Development of an intervention program for Alzheimer's family caregivers following diagnostic disclosure," Clinical Nursing Research, vol. 8, pp. 44-67, 2001. 

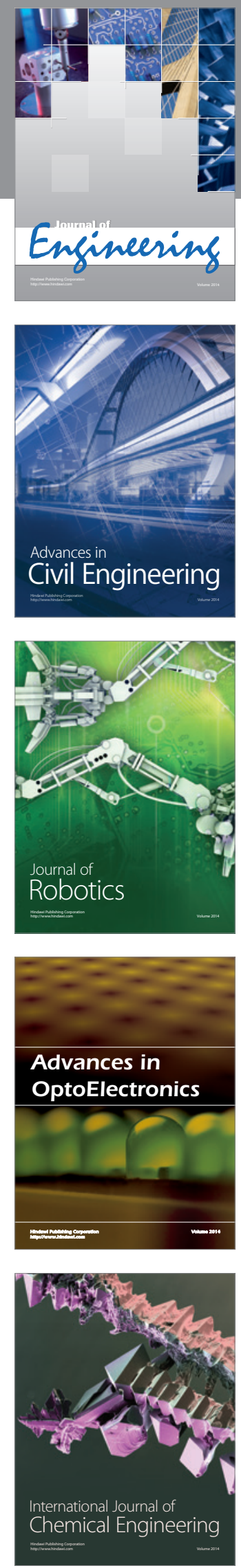

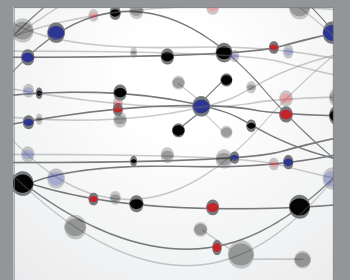

The Scientific World Journal
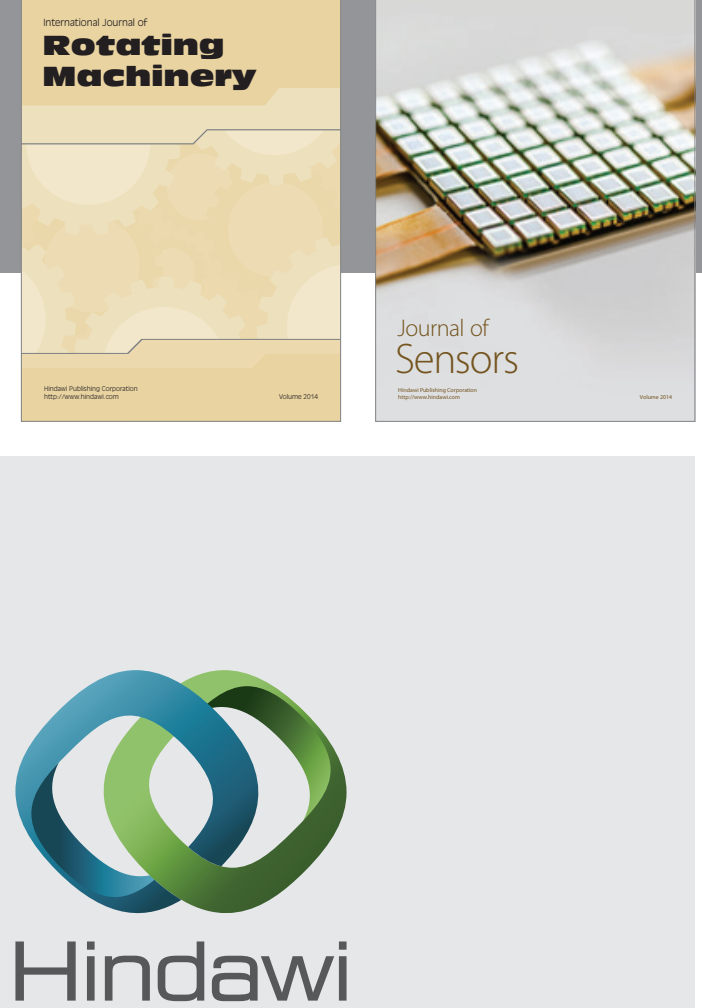

Submit your manuscripts at http://www.hindawi.com
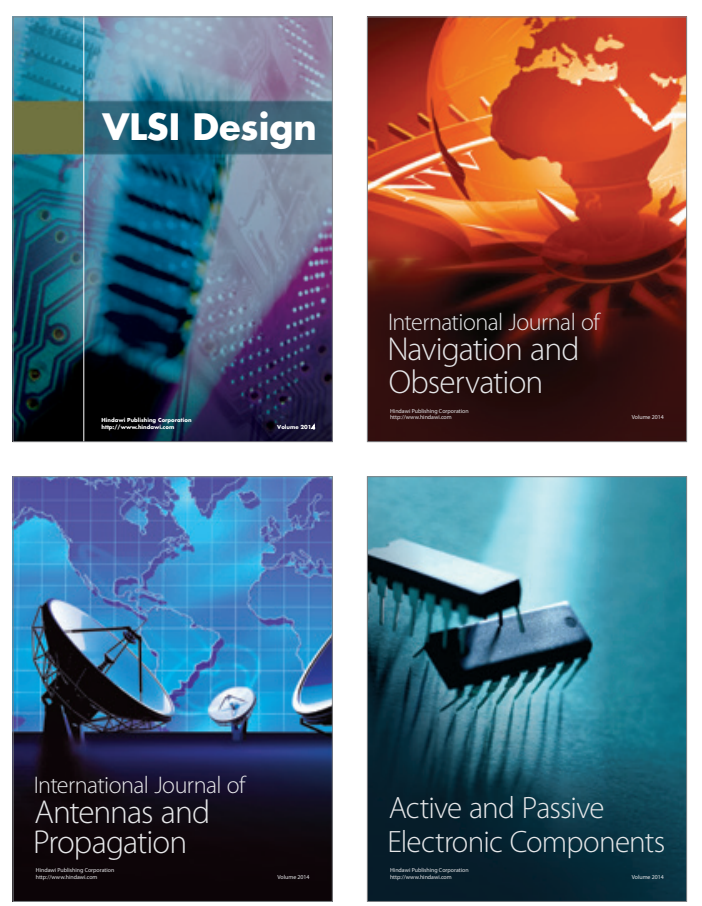
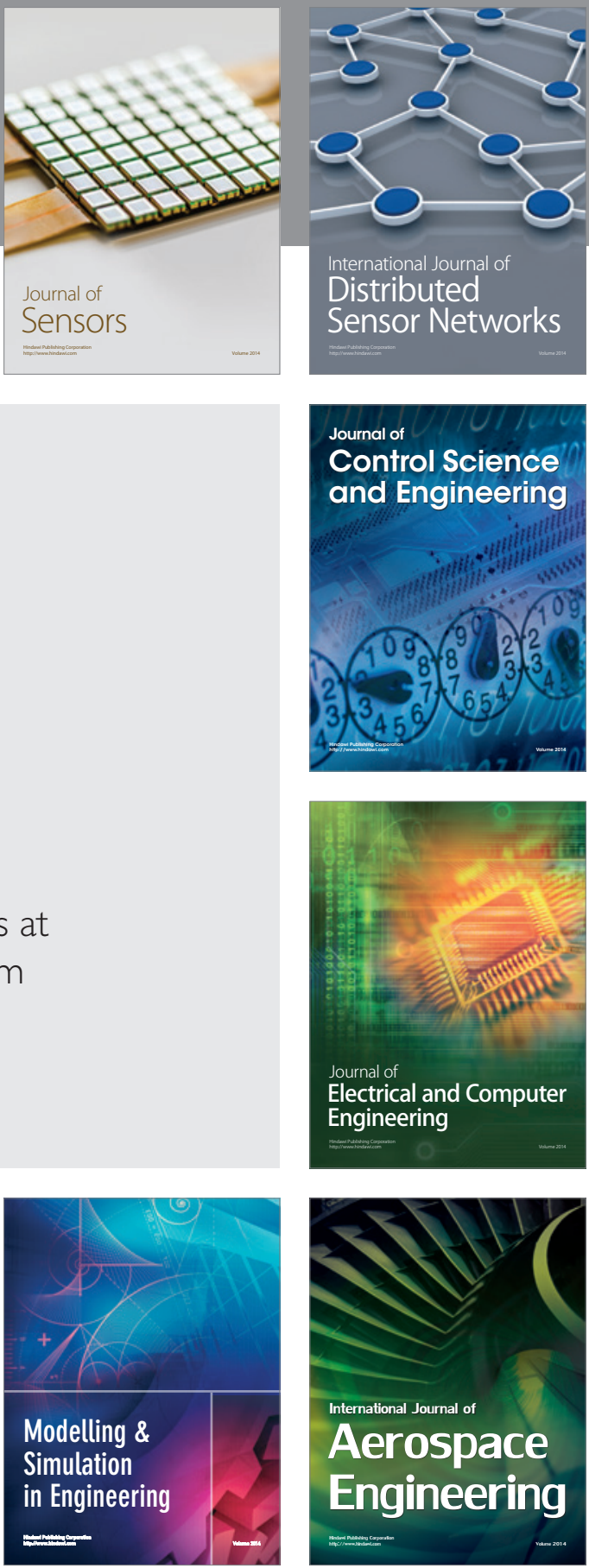

Journal of

Control Science

and Engineering
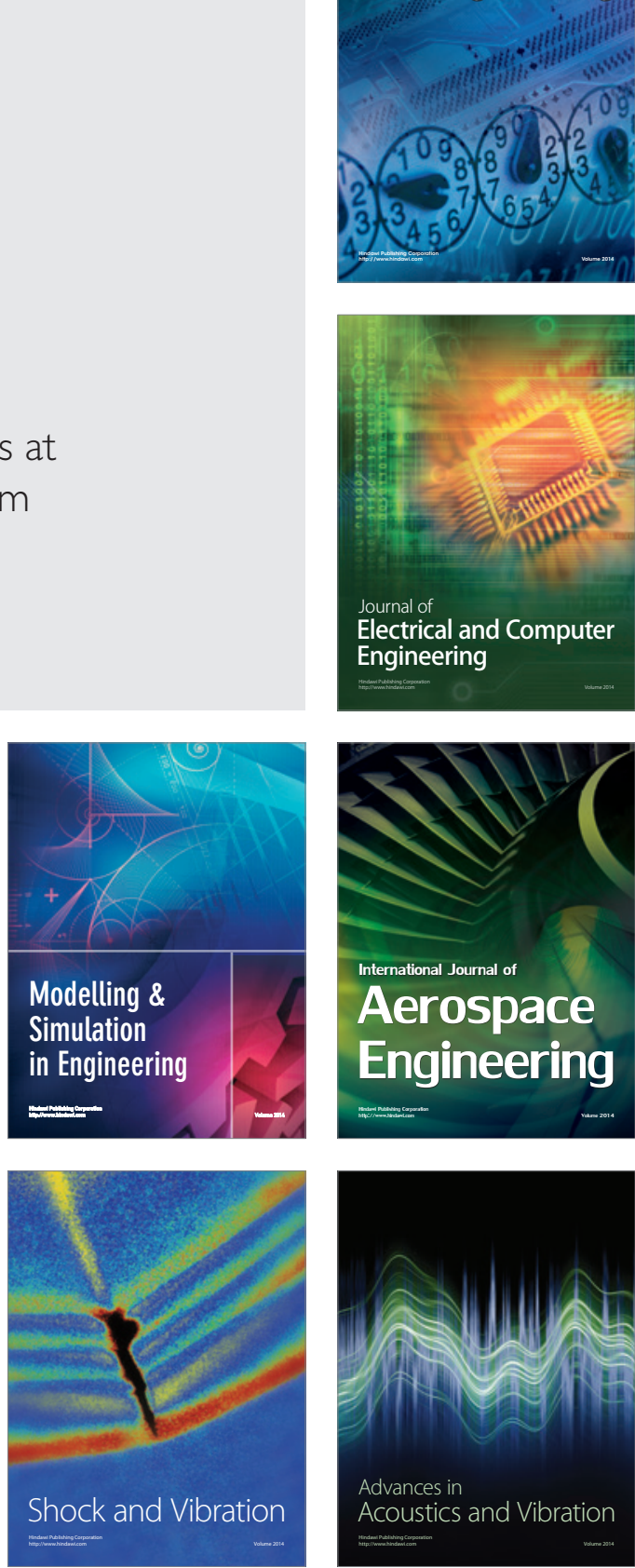